\title{
Flexible foraging behaviour of a sexually dimorphic seabird: large males do not always dive deep
}

\author{
Petra Quillfeldtt, ${ }^{1,}$, Simone Schroff ${ }^{1}$, Hendrika J. van Noordwijk ${ }^{1}$, \\ Andreas Michalik ${ }^{1}$, Katrin Ludynia ${ }^{2}$, Juan F. Masello ${ }^{1}$ \\ ${ }^{1}$ Max-Planck-Institut für Ornithologie, Vogelwarte Radolfzell, Schlossallee 2, 78315 Radolfzell, Germany \\ ${ }^{2}$ Animal Demography Unit, Department of Zoology, University of Cape Town, Rondebosch 7701, Cape Town, South Africa
}

\begin{abstract}
Sex differences in foraging behaviour have been explained by size dimorphism and/or avoidance of inter-sexual competition for depletable resources. To distinguish between these 2 hypotheses, we examined how intrinsic factors (sex-related differences) and extrinsic factors (year differences) shape the foraging behaviour of size-dimorphic imperial shags Phalacrocorax atriceps albiventer breeding at New Island, Falkland Islands/Islas Malvinas. We deployed time-depth and compass loggers to male and female imperial shags over 3 consecutive chick-feeding seasons. Males and females partly overlapped in coastal foraging areas, which were used mainly for benthic diving. Males additionally used offshore areas over deep water for shallow pelagic diving, suggesting that spatial segregation is involved in the avoidance of inter-sexual competition for food. Stable isotope data suggested differences in prey composition between the sexes, with consistently higher trophic levels in males, as expected for their larger size. Males were $27 \%$ heavier than females and reached greater maximum dive depths $(98.9 \pm 5.3 \mathrm{~m})$ than females $(54.1 \pm 2.9 \mathrm{~m})$. However, contrary to predictions based on body size dimorphism, the median dive depths of males were similar to those of females. While females used mainly benthic diving, males were more flexible in their benthic and pelagic foraging behaviour. Females also carried out more dives per day in all years, and deeper and longer dives than males in one year. As dive parameters differed strongly among the years, our results suggest that body size dimorphism and the avoidance of inter-sexual competition for food are involved in the evolution of sex-related differences in foraging in this species.
\end{abstract}

KEY WORDS: Diving behaviour - Behavioural plasticity $\cdot$ Optimal foraging $\cdot$ Stable isotope analysis Stable isotope mixing model $\cdot$ Sexual size dimorphism $\cdot$ Phalacrocorax atriceps

Resale or republication not permitted without written consent of the publisher

\section{INTRODUCTION}

Optimal foraging theory (MacArthur \& Pianka 1966, Schoener 1971) predicts that animals should forage so as to maximize net energy gain. Optimal foraging behaviour is subject to trade-offs between foraging and other activities, such as nest defence and predator avoidance. Sexes often have different solutions to these trade-offs, and this can in turn influence their foraging behaviour (e.g. Jenkins 1979, Clutton-Brock et al. 1982). As studies of sexual segregation in foraging have concentrated on size-dimorphic species, much of the variation has been attributed to size-based mechanisms, such as asymmetrical competition or differences in foraging efficiency (e.g. Weimerskirch et al. 1997, González-Solís et al. 2000). It has also been recognized that larger males must acquire more resources to attain greater size as well as to maintain it. The greater food requirements of large males would make it necessary for them to find prey patches that are denser, larger, or of higher quality prey; females, on the other hand, can forage efficiently on smaller or more ephemeral food patches. (e.g. Le Boeuf et al. 2000).

Diving is energetically expensive for birds, and this is especially true for deep dives and in cold water. For 
example, double-crested cormorants Phalacrocorax auritus have been shown to have diving metabolic rates about 6 times the basal metabolic rate (BMR) when diving to $10 \mathrm{~m}$ (Enstipp et al. 2006). Energy is required for increased locomotor effort and to counteract increased heat loss. Deeper water is colder, and, due to the increased pressure at depth, the plumage loses more of its insulating properties. Thus, in cold water, dive costs of up to 20 times the BMR have been estimated in birds (Grémillet et al. 2001, Enstipp et al. 2006). It has been noted recently (Shepard et al. 2009, 2010) that, due to reduced buoyancy, deep diving is proportionally less expensive metabolically than expected.

In many diving vertebrates that show sexual dimorphism, males and females pursue different foraging strategies (e.g. Japanese cormorants Phalacrocorax capillatus: Watanuki et al. 1996; northern elephant seals Mirounga angustirostris: Le Boeuf et al. 2000; grey seals Halichoerus grypus: Beck et al. 2003).

However, it has also been pointed out that some diving marine vertebrates that are monomorphic in body size differ in dive depth and other foraging parameters (e.g. thick-billed murres Uria lomvia: Woo et al. 1999; northern gannets Morus bassanus: Lewis et al. 2002; common guillemots Uria aalge: Thaxter et al. 2009). These differences are unlikely to have been mediated by body size, and could alternatively be explained by avoidance of inter-sexual competition for food.

In addition to size-based mechanisms, the strategy used to obtain food can be influenced by extrinsic factors such as the quality, availability and distribution of prey, the risk of predation (e.g. Heithaus et al. 2009) and climatic factors such as wind levels (e.g. Shaffer et al. 2001). Foragers would be expected to adjust their foraging strategies to maximize foraging efficiency (Fretwell \& Lucas 1969), especially during the chickfeeding period when energy requirements are highest, and therefore foraging effort should be highest.

Few seabirds show a high degree of sexual dimorphism. This is possibly a consequence of shared chick provisioning and nest defence by both parents, linked with monogamy (Schreiber \& Burger 2001). In most seabird species, males are slightly larger than females, although the reverse is also found, e.g. in skuas, frigatebirds and boobies. The difference is rarely more than $20 \%$ of mass. The cormorants of the so-called 'blue-eyed shag complex' (Van Tets 1976) are thus a notable exception, with a large sexual dimorphism (e.g. Malacalaza \& Hall 1988, Svagelj \& Quintana 2007). They also exhibit extreme dive depths relative to their body mass (maximum recorded dive depth $145 \mathrm{~m}$, Tremblay et al. 2005). This is even more surprising as they inhabit cold sub-Antarctic and Antarctic waters. Like other cormorants, blue-eyed shags are foot-propelled pursuit-divers. Although several authors have studied the diving behaviour of blueeyed shags (e.g. Wilson \& Quintana 2004, Quintana et al. 2007, Shepard et al. 2009, 2010), most studies were carried out in a single locality and time. Together, these studies suggest high flexibility in diving behaviour (e.g. Cook et al. 2008, Quintana et al. 2011), prey choice (e.g. Green \& Williams 1997), and benthic vs. pelagic dives (Tremblay et al. 2005), whether among sites (e.g. Cook et al. 2008), sexes (e.g. Kato et al. 1996, Quintana et al. 2010) or individuals (e.g. Kato et al. 2000, Cook et al. 2005).

In the present study, we used data loggers and stable isotope analysis in breeding male and female imperial shags over 3 successive breeding seasons to explore simultaneously the sexual and inter-annual differences in the diving behaviour, distribution and trophic level of the foraging birds. We specifically aimed to understand how intrinsic factors (sex differences) and extrinsic factors (year differences in response to different environmental conditions) shape (1) foraging daytime, foraging trip duration and total time spent diving throughout the day; (2) dive parameters (e.g. mean and maximum dive depth, dive durations, bottom-time, post-dive interval); (3) frequency of benthic vs. pelagic diving; (4) foraging-space use as related to coastal and offshore habitats; and (5) prey choice, as reflected in stable-isotope values.

\section{METHODS}

Study species. Up to 13 geographically isolated species of blue-eyed shags have been considered (SiegelCausey 1988). They are one of the main top predators feeding on coastal benthic fish (Casaux and BarreraOro 2006), mainly the Southern Ocean Notothenioidei. In addition, they are known to take a wide range of prey (e.g. Malacalaza et al. 1994, Punta et al. 2003, Ferrari et al. 2004, Michalik et al. 2010, Yorio et al. 2010), also including pelagic prey such as cephalopods and lobster krill Munida gregaria, a decapod crustacean (e.g. Thompson 1989, 1994). The diving behaviour of the Falkland/Malvinas Islands population of imperial shags Phalacrocorax atriceps albiventer (locally also known as king shag) has not yet been investigated. They are sexually dimorphic in size (body mass, wing and bill measurements), and previous studies of this and related species have suggested that, due to their larger size, males are able to dive deeper (e.g. Macquarie Island $P$. albiventer: Kato et al. 1999; Crozet shag P. melanogenis: Cook et al. 2007; Patagonian imperial shag: Quintana et al. 2011). Due to the larger bill size, males may also be able to take larger prey (e.g. Favero et al. 1998). 
Study site. This study was carried out during austral summers, between October 2006 and February 2009, at the Settlement colony at the New Island Nature Reserve, Falkland Islands $\left(51^{\circ} 43^{\prime} \mathrm{S}, 61^{\circ} 17^{\prime} \mathrm{W}\right)$, under license from the Falkland Islands Government (Environmental Office). More than 5000 pairs of imperial shags Phalacrocorax atriceps albiventer breed at New Island, about 3000 of these in the Settlement colony. The breeding season starts during early October with courtship and nest building. Egg-laying commenced in early November, and hatching in December, followed by a chick-rearing period of $\sim 60$ days. Chicks spent the first $6 \mathrm{wk}$ in the nest, and the remainder in crèches. Southern sea lions Otaria flavescens and orcas Orcinus orca are potential predators of adult shags at sea in the Falklands, but there are, to our knowledge, no reported cases of predation. This suggests that the current predation risk is low. It is further assumed that the effectiveness of cormorant escape behaviour does not vary spatially, e.g. between coastal and offshore areas (Heithaus et al. 2009).We therefore consider predation as a negligible impacting factor in shaping the foraging ecology of imperial shags.

Previous dietary analyses suggested that imperial shags from New Island feed extensively on lobster krill, as well as on benthic fish such as Patagonotothen sp. and squid (Thompson 1989). Diet sampling during our present study was in line with these findings, and indicated a variable diet, consisting of fish, crustaceans, and squid (Michalik et al. 2010). Fish samples were dominated by benthic species (e.g. rock cod Patagonotothen sp., frogmouth Cottoperca sp.), but also contained a mainly pelagic species (Patagonian sprat Sprattus fuegensis). Lobster krill, which can form superficial shoaling groups but which is also found at the sea bottom, was the dominant crustacean species, followed by prawn Campylonotus vagans. Squid samples mainly comprised Patagonian longfin squid Loligo gahi (a bentho-pelagic resident squid of the Falkland Island shelf) and the armhook squid Gonatus antarcticus.

During 3 successive breeding seasons, we monitored shag nests at selected study sites on a daily basis for laying dates, and every $5 \mathrm{~d}$ during the chick-rearing period. Adults were accustomed to our daily presence in the colony and responded with less escape behaviour than adults in areas visited only occasionally. In order to reduce the risk of nest desertion, we selected study nests with at least 2 chicks of intermediate age (from 10 to $30 \mathrm{~d}$ ).

Instrumentation. Adult imperial shags were captured by hand on their nests while guarding chicks. Preferably, we captured one partner while the second adult took over guard. However, if this was not possible, the nest and chicks had to be protected. The chicks were either protected by a plastic bowl placed over the nest, or they were removed from the nest and placed in cloth bags. A wooden board was placed on top to protect nests, so that neighbours could not remove nest material. Only one adult per nest was equipped with data-loggers, and different adults were used each year. To reduce handling stress, the head of each bird was covered with a hood during handling. We did not capture incoming adults before they had finished feeding their chicks.

At a safe distance from the colony, each bird was first ringed and weighed with a digital balance to the nearest $10 \mathrm{~g}$. Males were $27 \%$ heavier $(2.81 \pm 0.17 \mathrm{~kg})$ than females $(2.21 \pm 0.11 \mathrm{~kg}$, t-test: $t=13.4$, df 39, $\mathrm{p}<0.001)$. Each bird was then equipped with a precision temperature-depth recorder and a compass-temperature logger (PreciTD and CompassTlog, Earth \& Ocean Technologies, Kiel, Germany). The PreciTD loggers (TD, Fig. S1 in the Supplement at www.int-res.com/articles/suppl/ m428p271_supp.pdf) weighed $20 \mathrm{~g}$ and measured $19 \times$ $75 \mathrm{~mm}$, while the CompassTlog loggers (CT) weighed $14.5 \mathrm{~g}$ and measured $16 \times 65 \mathrm{~mm}$. The TD was fixed onto the upper side of 4 central tail feathers and the CT onto lower back feathers with Tesa tape (Tesa AG, Hamburg, Germany). It has previously been shown that this size of logger has no negative impact on blue-eyed shags over a short deployment period (e.g. Kato et al. 2000). The loggers were programmed to start at 03:00 h of the day after attachment and to record data every $1 \mathrm{~s}$ for a maximum of 6 consecutive days for the TD and $4 \mathrm{~d}$ for the CT, until the memory was filled or the batteries ran flat. Capture of each bird and attachment of loggers took from 15 to $25 \mathrm{~min}$; the birds were released to their nests immediately following logger attachment.

We equipped 18 imperial shags with loggers between 30 December 2006 and 22 January 2007 (hereafter 2006-07), 12 between 31 December 2007 and 12 January 2008 (2007-08) and 11 between 31 December 2008 and 11 January 2009 (2008-09). Due to battery or instrument failures and detachments, TD and CT sample sizes were not the same. Our final dataset consisted of dive data from 8 females and 7 males in 2006-07, 6 females and 6 males in 2007-08 and 6 females and 5 males in 2008-09, and compass data from 6 females and 7 males in 2006-07, 6 females and 4 males in 2007-08 and 5 females and 5 males in 2008-09.

At recapture (after 5 to $6 \mathrm{~d}$ ), we removed the loggers, weighed and measured the birds and took a blood sample for genetic and stable isotope analysis. A body condition index was calculated separately for the sexes, using tarsus and bill length as structural measures. Birds returned to their nests and resumed normal chickguarding behaviour within a few minutes of being released after both initial capture and recapture, and no chicks were lost during periods of device deployment. 
Analysis of diving data. Dive data were analysed with custom-written software as described in Mattern et al. (2007). Dive analysis encompassed identification of dive events and calculation of basic dive parameters for every dive. To compensate for erratic pressure fluctuations when the birds were at the surface, dive events were accepted only if depths $>1 \mathrm{~m}$ were registered. From the pressure data, basic parameters were determined, such as dive duration, dive depth and duration of post-dive interval (time spent at the surface). Three dive phases were distinguishable: the descent, the bottom phase and the ascent (Wilson 1995). The start of the bottom phase was defined as the time when the descent rate (i.e. vertical velocity) became less than $0.2 \mathrm{~m} \mathrm{~s}^{-1}$ after a continuous descent. Similarly, the end of the bottom phase was marked by an increase in vertical velocity of $>0.2 \mathrm{~m} \mathrm{~s}^{-1}$, followed by a continuous ascent to the surface. The time between start and end of the bottom phase was defined as the bottom duration. Descent and ascent rates were calculated from the depth change and transit time during the ascent or descent phase. The number of bottom wiggles was also calculated. Bottom wiggles are vertical direction changes during the bottom phase, which is an indicator of food intake (e.g. Takahashi et al. 2004).

To relate observed diving parameters to physiological diving abilities, we followed Tremblay et al. (2005) and Cook et al. (2008) in using the conclusions of an optimality model for diving endotherms (Walton et al. 1998). This model suggests that when birds deplete only the oxygen from the respiratory tract during a dive, short post-dive intervals on the surface (corresponding to the turnover time of respiratory gases) are needed to recover. Walton et al. (1998) suggested that diving animals should maximize their time being submerged, and thus foraging, relative to time lost to surface recovery. Such efficient dives would last as long as it takes to reach a maximum dive-duration to postdive interval (DD:PDI) ratio. Dives can thus be classified according to this maximum DD:PDI ratio and to the behavioural aerobic dive limit (bADL, e.g. Tremblay et al. 2005, Cook et al. 2008). The aerobic dive limit (ADL) is the dive duration after which a sudden increase in blood lactate concentration indicates an elevation in anaerobic metabolism, and dives longer than the ADL should be avoided. The bADL is a proxy of the ADL. Deep-diving air-breathing species can exceed this limit by utilising anaerobic metabolism for at least part of the dive, together with some physiological adjustment to conserve oxygen (e.g. peripheral vasoconstriction, bradycardia; Willmer et al. 2005) for long-duration dives. For example, only $52 \%$ of the measured dives made by thick-billed murres were within the calculated ADL (Croll et al. 1992). Direct evidence of dives that go beyond the lactate threshold has been found in Weddell seals Leptonychotes wed- dellii (Kooyman et al. 1983) and emperor penguins Aptenodytes forsteri (Ponganis et al. 1997). In the latter, the measured ADL ( $7 \mathrm{~min}$, with a transition time of between 5 and $7 \mathrm{~min}$; Ponganis et al. 1997) was close to the ADL calculated on the basis of $\mathrm{O}_{2}$ stores and diving metabolic rate (5 min; Kooyman and Ponganis 1990) and very close to the bADL based on analysis of the emperor penguins' diving duration vs. surface interval (8 min, Kooyman and Kooyman 1995), suggesting that the 3 methods are in good agreement.

We applied the last method, and estimated the bADL by plotting all data points of dive durations in relation to PDIs according to Kooyman et al. (1980), a method previously applied to blue-eyed shags (Tremblay et al. 2005, Cook et al. 2008). The bADL is defined by the point of inflection of an abrupt slope change, when PDIs begin to rise exponentially with dive durations, reflecting an increase in blood lactate concentration due to anaerobic metabolism. This changing point is determined visually on a graphic bottom-contour plot of the data.

Following Tremblay \& Cherel (2000), we calculated an index of benthic diving behaviour. This was based on the assumption that benthic divers dive serially to a specific depth, and thus consecutive dives reach the same depth zone. Such dives are called intra-depth zone (IDZ) dives (Tremblay \& Cherel 2000). The IDZ was defined as the depth $\pm 10 \%$ of the maximum depth reached by the preceding dive (Tremblay \& Cherel 2000). In rockhopper penguins Eudyptes chrysocome filholi, the proportion of IDZ dives within a data set of benthic dives was $94 \%$, compared to $40 \%$ for series classed as pelagic dives, thus providing a measure of the relative importance of benthic vs. pelagic diving. The method has previously been used in blue-eyed shags (Tremblay et al. 2005).

Statistical tests were performed with SPSS 11.0.0. Kolmogorov-Smirnov tests were used to test for normality (all $p>0.2$ ). Homogeneity of error variances was checked by plotting residuals against predicted values.

In total, we analysed 18767 dive events, evenly distributed among 11 to 15 individuals from 3 years (6791 dives in 2006-07, 6250 in 2007-08 and 5726 in 2008-09). The parameters of dive events were not normally distributed. Thus we used medians to obtain parameters for each foraging trip. Because these medians were not normally distributed either, we again used medians to determine dive parameters for each individual. These latter medians fulfilled the assumptions of parametric statistics, and were used as dependent variables in General Linear Models (GLM) with sex and year as factors. Initially, we included the interaction between the year and sex factors into the model, but removed it if it did not reveal significance (e.g. Engqvist 2005). Separate GLMs were run for each trip or dive parameter. As a measure of effect sizes in 
GLMs we used partial eta-square values $\left(\eta^{2}\right.$, i.e. the proportion of the effect + error variance that is attributable to the effect). The sums of the partial eta-square values are not additive (see e.g. http://web.uccs.edu/ lbecker/SPSS/glm_effectsize.htm).

Multiple testing of essentially the same $\mathrm{H}_{0}$ and/or the same data set required some error-level correction. We did this using Fisher's omnibus test. This procedure combines a number of $P$-values into a single chisquare-distributed variable with its degrees of freedom equalling twice the number of $P$-values (Haccou \& Meelis 1994, Quinn \& Keough 2002).

Analysis of CT data. CT data were processed using MTComp software (Compass-Tlog, Multitrace, JSS, Laboe, Germany). We adapted the criteria of other studies using similar devices (e.g. Ropert-Coudert et al. 2004, Thaxter et al. 2009) to distinguish between 4 activities: (1) nest attendance, characterized by stable compass signals; (2) flight, recognized by consistent low-amplitude oscillations; (3) time at sea surface, determined by a very stable temperature and 'noisy' compass signals; and (4) diving, defined by repeated changes in compass signals when birds upended to descend underwater and ascended back to the surface, together with characteristic temperature patterns.

Tracks of birds during trips were reconstructed via dead reckoning (see Wilson \& Wilson 1988, Wilson et al. 1991) using the MTComp software, by combining data on direction of travel during each period of flight, the duration of the flight period, and a flight speed of $22.5 \mathrm{~m} \mathrm{~s}^{-1}$. This speed was obtained at New Island from field measurements of the duration of flight (to the nearest $0.01 \mathrm{~s}$ ) along a sector of $178 \mathrm{~m}$ of a commonly used flight path towards the colony. The measurements were carried out during $4 \mathrm{~d}$ with different wind conditions. We registered flight speeds ranging from 19.3 to $40.4 \mathrm{~m} \mathrm{~s}^{-1}(\mathrm{n}=15)$, the median flight speed being $22.5 \mathrm{~m} \mathrm{~s}^{-1}$. These flight speeds concurred well with data from 4 GPS units (2 males, 2 females, mean 20.6, SD $5.1 \mathrm{~m} \mathrm{~s}^{-1}$, unpubl. data) for birds from the same colony. Direction and distance of travel were corrected for wind speed and wind direction (sampled hourly) using weather data from our own autonomous professional weather station at New Island (ca. $1 \mathrm{~km}$ from the Settlement colony; Campbell Scientific). An endpoint correction was applied to constrain tracks to start and finish at the same location (see Wilson et al. 1991 for further details).

Positional data $\left(\mathrm{s}^{-1}\right)$ obtained from the analysis of CT data were used to plot and analyse the trips made by the birds using ArcGIS 9.3. The general areas used by the birds, as derived from the CTs, accorded with those from GPS loggers for the 2009 data set (Masello et al. 2010; see also Fig. S2 in the Supplement at www.intres.com/articles/suppl/m428p271_supp.pdf). The total distance travelled on each trip was calculated by summing data over successive time steps (1 s). For each trip, the maximum distance from the colony was calculated as the linear distance to the point in the plotted trip that was farthest away from the geographic coordinates of the departure colony, determined by GPS. Trip duration was taken as the elapsed time between departure from and return to the colony. To avoid pseudo-replication, we calculated the median of all trip parameters for each bird, and used these data in the comparisons between sexes and years.

The nonparametric fixed kernel density estimator (Wood et al. 2000) was used to determine the 20,40,60 and $80 \%$ density contour areas (the estimated foraging range), which are a weighted frequency of locations within the specified radius (Wood et al. 2000). Kernel densities do not require serial independence of observations when estimating foraging ranges (de Solla et al. 1999). Density contours corresponding to kernels were calculated for locations in a Lambert Equal-Area Azimuthal Projection centred on the South Pole. ArcGIS 9.3 was used for calculations, together with Hawth's Analysis Tools for ArcGIS (Beyer 2004).

Stable isotope analysis. Nitrogen stable isotope values $\left(\delta^{15} \mathrm{~N}\right)$ mainly reflect the trophic level of assimilated prey, with an increase of 1 to $5 \%$ per trophic level (Minagawa \& Wada 1984, Owens 1987). Carbon stable isotope values $\left(\delta^{13} \mathrm{C}\right)$ mainly reflect the carbon source in a food chain and therefore differ among foraging locations. Large-scale changes in latitude (e.g. Quillfeldt et al. 2005, 2008) can be superimposed on smaller-scale changes like nearshore vs. offshore habitats or benthic vs. pelagic food webs. Furthermore, a change in $\delta^{13} \mathrm{C}$ can indicate a switch between isotopically distinctive prey types that can migrate to a foraging habitat.

We analysed carbon and nitrogen stable isotopes of red blood cells and prey items obtained from food regurgitated during handling or spilled during chickfeeding (Michalik et al. 2010). The main prey items were lobster krill $(\mathrm{n}=6)$; Patagonian longfin squid $(\mathrm{n}=$ $5)$; and fish Agonopsis chiloensis $(n=1)$, Cottoperca gobio $(n=2)$, Patagonotothen squamiceps $(\mathrm{n}=1)$, $P$. wiltoni $(\mathrm{n}=1)$, Patagonian sprat $(\mathrm{n}=1)$, and a member of the taxon Zoarcidae.

Of the 2 major constituents of whole blood - blood plasma and red blood cells - plasma has a much faster turnover, with a half-life of $\sim 3 \mathrm{~d}$, while red blood cells have a half-life of $\sim 30 \mathrm{~d}$, therefore integrating a much longer time (Hobson \& Clark 1993).

Dried diet samples were lipid-extracted in a Soxhlet apparatus using petroleum ether for at least $6 \mathrm{~h}$ until all lipids were extracted, and the liquid was no longer coloured by any remaining lipids. The crustaceans were acid-washed to remove carbonate, with 
$3.8 \mathrm{w} / \mathrm{w} \% \mathrm{HCl}$ being slowly added until no further $\mathrm{CO}_{2}$-gas was formed. The remaining tissue was cleaned with deionised water. Afterward all samples were dried at $60^{\circ} \mathrm{C}$ for at least $1 \mathrm{~d}$. Blood samples were centrifuged and red blood cells dried at $38^{\circ} \mathrm{C}$ in an oven for further analysis. Aliquots of $\sim 0.7 \mathrm{mg}$ of each dry sample were weighed into tin capsules.

Stable isotope ratios of $\mathrm{C}$ and $\mathrm{N}$ were analysed by continuous-flow isotope-ratio mass spectrometry (CFIRMS) with a Costech ECS 4010 elemental analyser linked to a Thermo Electron Delta Plus XP mass spectrometer. The stable isotope ratios were expressed in $\delta$-values as parts per thousand (\%) according to the following equation: $\delta X=\left[\left(R_{\text {sample }} \div R_{\text {standard }}\right)-1\right] \times 1000$, where $X$ is the heavy ${ }^{13} \mathrm{C}$ or ${ }^{15} \mathrm{~N}$ isotope and $R$ is the ratio ${ }^{13} \mathrm{C}:{ }^{12} \mathrm{C}$ or ${ }^{15} \mathrm{~N}:{ }^{14} \mathrm{~N}$, respectively. $R_{\text {standard }}$ is the isotope ratio of the standard international references PeeDee Belemnite for carbon and AIR for nitrogen. Instrument drifts over time were corrected by means of the repeated measurement of 3 lab standards (gelatine and 2 isotopically distinctive alanines). Errors were small, with $\mathrm{SD}<0.04 \%$ for $\mathrm{C}$ and $0.15 \%$ for $\mathrm{N}$, based on measurements of standardized tryptophan.

Stable isotope mixing model. To estimate diet compositions based on stable isotope values, we applied a Bayesian model in SIAR 4.0 (Stable Isotope Analysis in R, Parnell et al. 2008) that runs under the free software R (R Development Core Team, 2009). This model allows the incorporation of sources of uncertainty, in particular the variability in isotope signatures of prey species (Inger \& Bearhop 2008, Moore \& Semmens 2008). SIAR uses Markov Chain Monte Carlo modelling, taking data on animal isotopes and fitting a Bayesian model to their dietary habits based upon a Gaussian likelihood with a Dirichlet prior mixture on the mean. The model assumes that each target value (i.e. the stable isotope data of each individual) comes from a Gaussian distribution with an unknown mean and SD. The structure of the mean is a weighted combination of the food sources' isotopic values. The SD depends on the uncertainty around the fractionation corrections and the natural variability between target individuals within a defined group (in this case, males and females). We used the standard setting (20000 iterations), and the following mean isotopic discrimination rates for diet-blood in birds (reviewed in Caut et al. 2009): $\delta^{15} \mathrm{~N}=2 \%$, $\delta^{13} \mathrm{C}=0.6 \%$. SD was set to 0.5 for $\delta^{15} \mathrm{~N}$ and $\delta^{13} \mathrm{C}$, which is at the upper end of the range of values suggested by Caut et al. (2009). We included the 3 major prey types (fish, squid and lobster krill) as sources in the mixing model, given the very minor importance of all other prey (e.g. prawns; Michalik et al. 2010). We applied the SIAR model only to data of adults in 2008-09, as we had matching prey data for this breeding season.

\section{RESULTS}

\section{Daily provisioning behaviour}

Male as well as female imperial shags made from 1 to 3 trips $\mathrm{d}^{-1}$ (Table 1, Fig. S3 in the Supplement at www.int-res.com/articles/suppl/m428p271_supp.pdf). The number of trips $\mathrm{d}^{-1}$ made by females varied among years $\left(\chi^{2}=16.3\right.$, df $=4, p=0.003$; Fig. S3a in the Supplement). In 2006-07 and 2007-08, females made 1 or 2 trips $\mathrm{d}^{-1}$. The number of females with only 1 trip $\mathrm{d}^{-1}$ was lower in 2008-09; some carried out 3 trips $\mathrm{d}^{-1}$ in that year. While the same trend of fewer one-trip days was observed for males in 2008-09, the differences were not significant $\left(\chi^{2}=4.9\right.$, df $=4, \mathrm{p}=0.294$; Fig. S3b).

The first trip of the day was the longest and contained the most diving events. Females initiated this trip early in the morning, while males foraged in the afternoon, after the female returned. This behavioural difference was highly conserved, as shown by a major difference in start-time between the sexes (Table 1, $\left.F_{1,38}=193.6, \mathrm{p}<0.001, \chi^{2}=0.85\right)$, but not among years $\left(F_{2,38}=2.2, \mathrm{p}=0.212, \chi^{2}=0.12\right)$.

Males undertook fewer dives $\mathrm{d}^{-1}$ than females (Table 2). Over the day, they spent less time foraging and under water and had less bottom time (Table 2) than females. The time under water and the bottom time also differed among years, with particularly short underwater times in 2008-09 (Table 2).

\section{Spatial distribution}

Females carried out foraging trips to the coastal areas around the southern part of New Island (especially South Harbor Bay) and to the southeast, between New Island (Fig. 1a, in black) and Beaver Island (Fig. 1a, in grey to the south of New Island) and Weddell Island (Fig. 1a, in grey to the southeast of New Island), to an area known as the Grey Channel, which contains some smaller islands, like Penn and Quaker Islands. Kernel analysis indicated that they spent considerable time in both areas on opposite sides of the Grey Channel (Fig. 1b).

According to kernel analysis, males also used these coastal areas for most of their foraging time (Fig. 1b). In addition, they carried out foraging trips to offshore areas of deeper waters toward the NW (Fig. 1), areas that were exclusively visited by males. There, male shags made some deep dives (>100 m), but mainly engaged in shallow diving (Fig. S4 in the Supplement).

The overlap observed in the foraging areas used by females and males varied among years. The $80 \%$ density contour areas of the kernel analyses over- 
Table 1. Phalacrocorax atriceps albiventer. Trip parameters (mean \pm SE) of first to third foraging trips during the day, separately for males and females. Startand end-time of foraging is the time when the first and last dive event occurred.

\begin{tabular}{|c|c|c|c|c|c|c|}
\hline \multirow[t]{2}{*}{ Trip } & \multirow[t]{2}{*}{$\mathrm{N}$} & \multicolumn{3}{|c|}{ Foraging time (h:min) } & \multicolumn{2}{|c|}{ - Dives (n) } \\
\hline & & Start & End & Duration & Mean & Maximum \\
\hline \multicolumn{7}{|c|}{ Males } \\
\hline 1 & 97 & $12: 37 \pm 0: 11$ & $17: 43 \pm 0: 23$ & $5: 07 \pm 0: 24$ & $67.1 \pm 5.5$ & 265 \\
\hline 2 & 41 & $17: 47 \pm 0: 14$ & $20: 12 \pm 0: 10$ & $2: 25 \pm 0: 15$ & $31.4 \pm 3.7$ & 120 \\
\hline 3 & 2 & $20: 32 \pm 0: 05$ & $21: 04 \pm 0: 29$ & $0: 33 \pm 0: 24$ & $8.5 \pm 5.5$ & 14 \\
\hline \multicolumn{7}{|c|}{ Females } \\
\hline 1 & 109 & $4: 41 \pm 0: 06$ & $11: 37 \pm 0: 09$ & $6: 56 \pm 0: 09$ & $92.9 \pm 4.5$ & 209 \\
\hline 2 & 44 & $15: 19 \pm 0: 11$ & $16: 27 \pm 0: 11$ & $1: 08 \pm 0: 10$ & $18.4 \pm 3.3$ & 131 \\
\hline 3 & 3 & $19: 11 \pm 0: 40$ & $19: 48 \pm 0: 22$ & $0: 38 \pm 0: 19$ & $7.7 \pm 2.9$ & 13 \\
\hline
\end{tabular}
$\mathrm{N}$ is the number of trips

period than females (Table S1, Fig. 2b). The deepest dives recorded were $97 \mathrm{~m}$ in females and $122 \mathrm{~m}$ in males, and the longest dive durations were $279 \mathrm{~s}$ and 307 s, respectively. These differences were maintained during all 3 years (Fig. 2b).

The median dive parameters showed differences, however, among years (Table S1 in the Supplement, Fig. 2a). In particular, 2008-09 was characterized by shorter and shallower dives by both sexes than the other 2 years. The years also differed in the cumulative underwater and bottom times per day (Table 2). Year influenced 3 of 9 maximum dive lapped by $22 \%$ in the years 2006-07 and 2007-08, but only by $6 \%$ in $2008-09$.

The duration of foraging trips was consistently longer in female shags (Table 3). However, maximum distances from the colony and trip lengths did not differ between the sexes in 2006-07 and 2007-08 (Table 3), with common trip lengths around $50 \mathrm{~km}$. Males carried out foraging trips nearly twice as long in the third year, and this was also reflected in higher maximum distances from the colony in males in 2008-09 (Fig. 1a, Table 3).

\section{Sex- and year-related differences in dive parameters}

Males and females did not differ in their median dive parameters, such as median dive depth and duration (Table S1 in the Supplement at www.int-res.com/ articles/suppl/m428p271_supp.pdf, Fig. 2a). However, they differed in their maximum dive parameters, with males being able to dive faster, deeper and for a longer parameters (Table S2 in the Supplement). An overall effect was detected (Table S2), although weaker than for median dive parameters.

The distribution of dive depths (Fig. 3) differed among years. In 2006-07 and 2007-08, dive depths of males showed 3 peaks, with the most common dive depths around $10 \mathrm{~m}$ and from 30 to $40 \mathrm{~m}$, with a smaller number in the range of 90 to $100 \mathrm{~m}$. In contrast, males in 2009 lacked the peak around 30 to $40 \mathrm{~m}$, and over $50 \%$ of dives were $<10 \mathrm{~m}$ deep (Fig. 3). Female behaviour changed less drastically, although some features were similar to those observed in males. In 2006-07 and 2007-08, they showed a major peak at 10 to $30 \mathrm{~m}$, a lower peak in the 30 to $50 \mathrm{~m}$ range, and only a few dives of $>60 \mathrm{~m}$. In 2008-09, the $0-10 \mathrm{~m}$ depth range became the most important and the difference between the sexes reversed: while males had higher maximum dive depths, females had higher median dive durations and dive depths (Fig. 2).

Moreover, the relative importance of benthic vs. pelagic diving, described by the IDZ index, differed

Table 2. Phalacrocorax atriceps albiventer. Results of GLMs, showing influence of year and gender on daily diving activity (2006-07: 8 females, 7 males, 2007-08: 6 females, 6 males, 2008-09: 6 females, 5 males). To avoid pseudo-replication, 1 data point was used per individual for each parameter. It was calculated from the means of all days $(n=3$ to $6 \mathrm{~d}$ per individual). Only significant values are detailed. NS = no significant effect

\begin{tabular}{|c|c|c|c|c|c|c|c|c|}
\hline & $\begin{array}{l}\text { Males }(n=18) \\
\text { Mean } \pm \text { SE }\end{array}$ & $\begin{array}{c}\text { Females }(n=20) \\
\text { Mean } \pm \text { SE }\end{array}$ & $F$ & $\begin{array}{c}\text { Year effect } \\
\mathrm{p}\end{array}$ & $\overline{\eta^{2}}$ & $\bar{F}$ & $\begin{array}{c}\text { Sex effect } \\
p\end{array}$ & $\overline{\eta^{2}}$ \\
\hline Dives (no. $\mathrm{d}^{-1}$ ) & $74.9 \pm 9.5$ & $103.6 \pm 8.9$ & NS & 4.7 & 0.038 & 0.12 & & \\
\hline Time in dive bouts $\left(\mathrm{h} \mathrm{d}^{-1}\right)$ & $6.2 \pm 0.5$ & $7.4 \pm 0.2$ & NS & & & & & \\
\hline Time under water $\left(\mathrm{h} \mathrm{d}^{-1}\right)$ & & & 4.0 & 0.027 & 0.19 & 11.8 & 0.002 & 0.26 \\
\hline $2006-2007$ & $1.9 \pm 0.3$ & $2.4 \pm 0.1$ & & & & & & \\
\hline $2007-2008$ & $1.9 \pm 0.4$ & $2.7 \pm 0.2$ & & & & & & \\
\hline $2008-2009$ & $1.0 \pm 0.4$ & $2.1 \pm 0.2$ & & & & & & \\
\hline Bottom time $\left(\mathrm{h} \mathrm{d}^{-1}\right)$ & & & 4.8 & 0.015 & 0.22 & 11.2 & 0.002 & 0.25 \\
\hline $2006-2007$ & $1.1 \pm 0.2$ & $1.4 \pm 0.1$ & & & & & & \\
\hline $2007-2008$ & $1.1 \pm 0.3$ & $1.7 \pm 0.2$ & & & & & & \\
\hline 2008-2009 & $0.4 \pm 0.2$ & $1.1 \pm 0.1$ & & & & & & \\
\hline IDZ index & see Fig. 3 & see Fig. 3 & 4.1 & 0.025 & 0.19 & 12.0 & 0.001 & 0.26 \\
\hline
\end{tabular}


a Flight paths
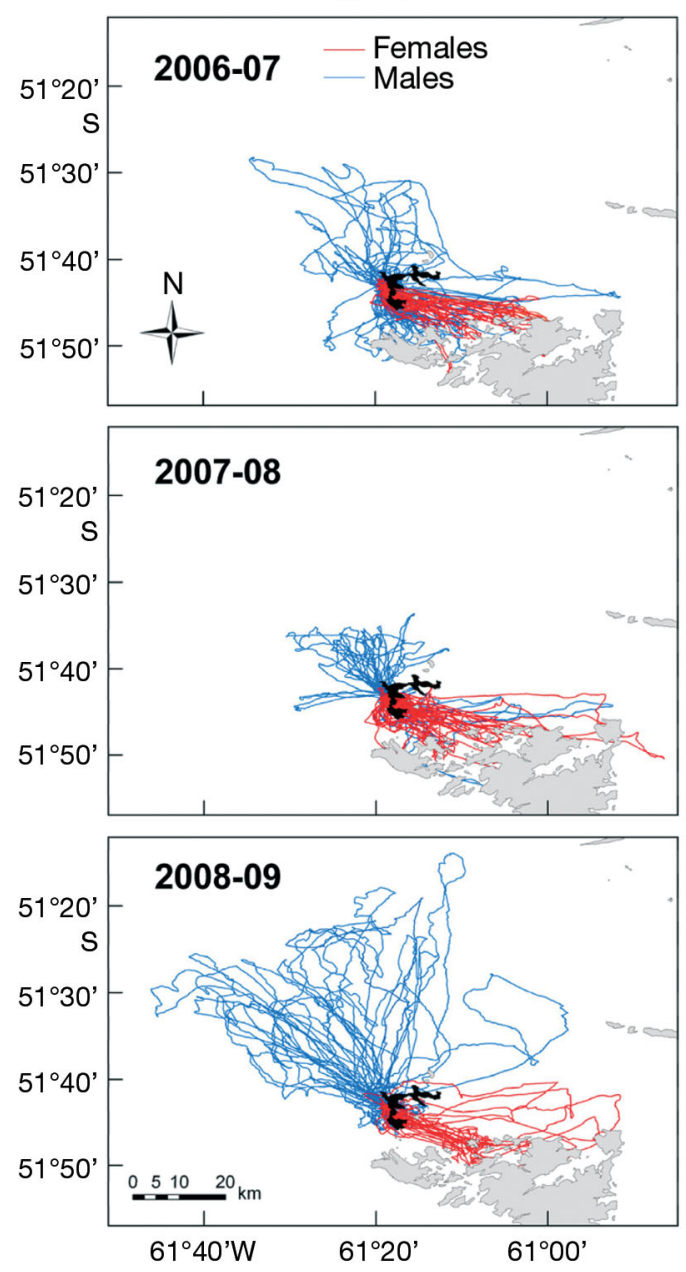

b Kernel distributions
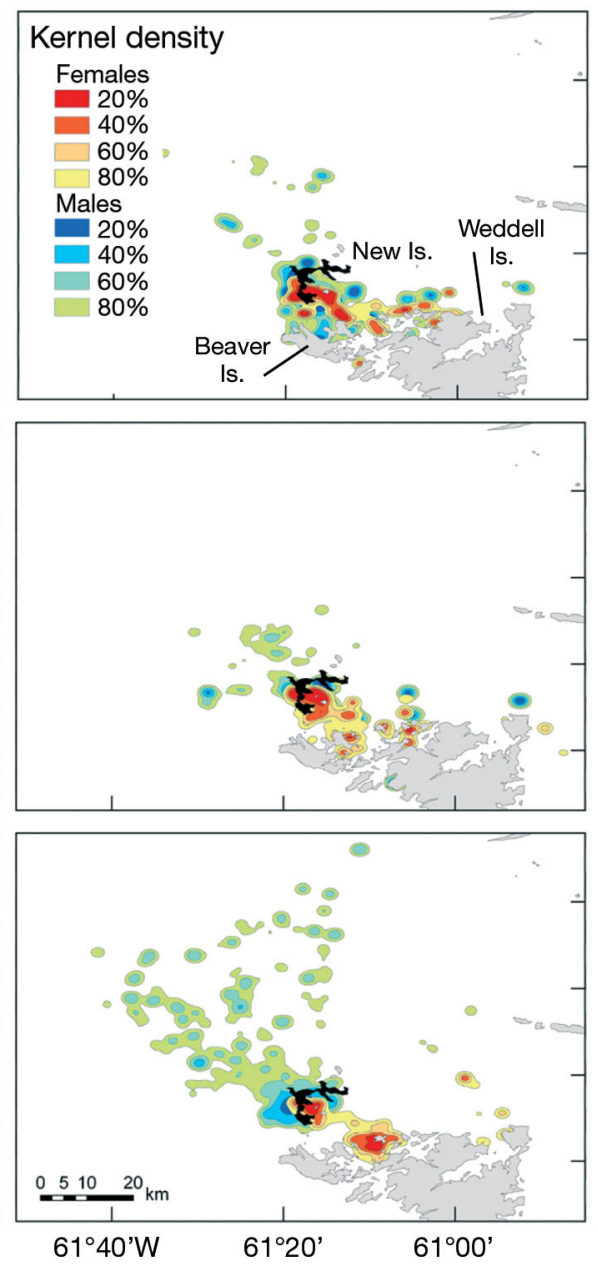

c SSTA
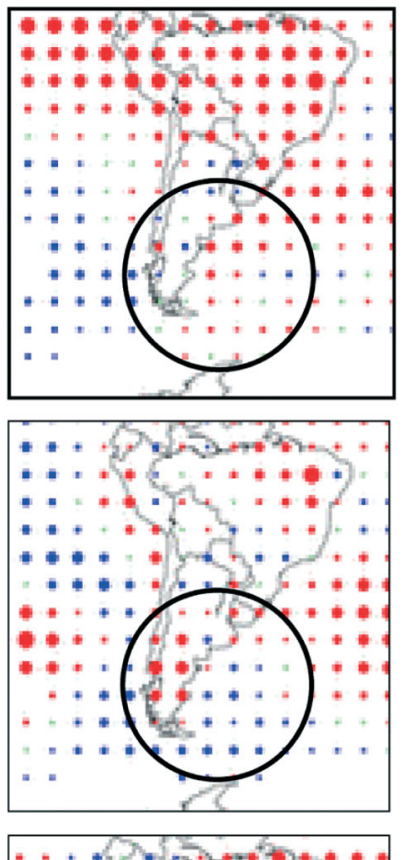

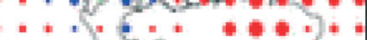

". +

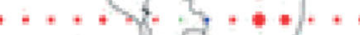

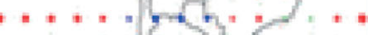

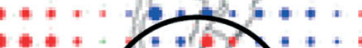

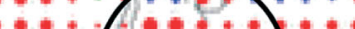

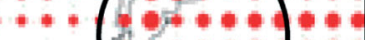

$++\cdot(25+0+1)+4$

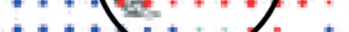

i.

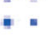

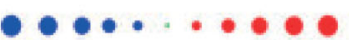

$\begin{array}{llllll}-5 & -3 & -1 & 1 & 3 & 5^{\circ} \mathrm{C}\end{array}$

Fig. 1. Phalacrocorax atriceps albiventer. Foraging trips (a) and kernel distributions (b) of male and females breeding at New Island (black) over 3 years. (c) Sea surface temperatures (SSTA) for the same 3 years (source: http://www.ncdc.noaa.gov/sotc). Breeding success was greater in 2007-08 (1.94 \pm 0.15 chicks per nest) than in 2006-07 (1.37 \pm 0.10$)$ and 2008-09 (1.39 \pm 0.13$)$; ANOVA: $F_{116,2}=5.9, \mathrm{p}=0.004$

between the sexes and among years (Fig. 3, Table 2). Males did more pelagic diving, and post hoc tests indicated that benthic dives were less important in 2008-09 than in the other 2 years.

\section{Classification of dives}

A peak in the DD:PDI ratio was detected for dives lasting $29 \mathrm{~s}$ in males and $27 \mathrm{~s}$ in females; this ratio decreased for longer-duration dives (Fig. S5 in the Supplement). We used bottom-contour plots of the relation between PDI and DD separately for males and females (Fig. S6 in the Supplement), and detected a variation in the scattergram for dives, suggesting a higher bADL for males than females (Fig. S6).
Although the specifics of choosing the points of inflection are somewhat subjective, the differences observed between the sexes were substantial (Fig. S6).

We then classified the dives into 3 categories (Fig. 4): Dur1 dives (from 0 to $27 \mathrm{~s}$ in females and from 0 to $29 \mathrm{~s}$ in males; see also Fig. S5); Dur2 dives (from 27 to $180 \mathrm{~s}$ in females and from 29 to $220 \mathrm{~s}$ in males) and Dur3 dives (from 180 to $297 \mathrm{~s}$ in females and from 220 to $307 \mathrm{~s}$ in males; see also Fig. S6). Dur1 dives were more frequent in males than females in all years $\left(\chi^{2}\right.$ tests, all $\mathrm{p}<0.001$ ). Dur2 dives were more frequent in females than males in all years $\left(\chi^{2}\right.$ tests, $\mathrm{p}<0.001$ in 2006-07 and 2008-09, p = 0.018 in 2007-08). Potentially anaerobic Dur3 dives were relatively rare (Fig. 4). Both sexes presented strong differences in distribution of dive durations among years (females: $\chi^{2}=1099$, df $=4$, $p<$ 
Table 3. Phalacrocorax atriceps albiventer. Parameters of foraging trips during chick-feeding, determined using CT loggers. Median data for each individual were compared, i.e. 1 data point per individual was used to determine mean $\pm \mathrm{SE}$, and to test for sex differences, interactions between sex and season (using GLM) and year differences (using ANOVA, separately for males and females, with Tukey post hoc tests). Statistically significant results are bolded; homogenous subsets in ANOVA for year differences are marked with superscript letters

\begin{tabular}{|c|c|c|c|c|c|c|c|c|c|c|c|}
\hline & & $\mathrm{n}$ & \multicolumn{3}{|c|}{ Distance from colony $(\mathrm{km})$} & \multicolumn{3}{|c|}{ Trip length (km) } & \multicolumn{3}{|c|}{ Trip duration (min) } \\
\hline \multirow[t]{2}{*}{ 2006-2007 } & Male & 7 & \multicolumn{3}{|c|}{$14.7 \pm 1.7^{\mathrm{a}, \mathrm{b}}$} & \multicolumn{3}{|c|}{$46.8 \pm 4.5^{\mathrm{a}}$} & \multicolumn{3}{|c|}{$298.6 \pm 33.0$} \\
\hline & Female & 6 & \multicolumn{3}{|c|}{$13.7 \pm 2.7$} & \multicolumn{3}{|c|}{$47.2 \pm 7.3$} & \multicolumn{3}{|c|}{$428.1 \pm 18.2$} \\
\hline $2007-2008$ & Male & 4 & \multicolumn{3}{|c|}{$12.5 \pm 1.9^{\mathrm{a}}$} & \multicolumn{3}{|c|}{$39.1 \pm 6.8^{\text {a }}$} & \multicolumn{3}{|c|}{$190.3 \pm 69.1$} \\
\hline & Female & 6 & \multirow{2}{*}{\multicolumn{3}{|c|}{$13.4 \pm 3.5$}} & \multicolumn{3}{|c|}{$48.9 \pm 10.0$} & \multicolumn{3}{|c|}{$416.4 \pm 41.1$} \\
\hline 2008-2009 & Male & 5 & \multicolumn{2}{|c|}{$26.4 \pm 5.9^{b}$} & & \multicolumn{3}{|c|}{$95.4 \pm 13.0^{b}$} & \multicolumn{3}{|c|}{$280.4 \pm 75.8$} \\
\hline & Female & 5 & \multicolumn{3}{|c|}{$14.8 \pm 3.2$} & \multicolumn{3}{|c|}{$55.6 \pm 9.9$} & \multicolumn{3}{|c|}{$395.8 \pm 23.2$} \\
\hline & & & \multicolumn{3}{|c|}{ Distance from colony } & \multicolumn{3}{|c|}{ Trip length } & \multicolumn{3}{|c|}{ Trip duration } \\
\hline & & & $F$ & df & $\mathrm{p}$ & $F$ & $\mathrm{df}$ & $\mathrm{p}$ & $F$ & df & $\mathrm{p}$ \\
\hline Sex (GLM) & & & 2.0 & 1,32 & 0.172 & 1.9 & 1,32 & 0.183 & 18.4 & 1,32 & $<0.001$ \\
\hline Year $\times \operatorname{Sex}($ & (M) & & 1.9 & 2,31 & 0.176 & 4.2 & 2,31 & 0.026 & 0.9 & 2,31 & 0.440 \\
\hline \multicolumn{12}{|c|}{ Year differences (ANOVA) } \\
\hline Male & & & 4.1 & 2,13 & 0.040 & 12.6 & 2,13 & 0.001 & 0.9 & 2,13 & 0.417 \\
\hline Female & & & 0.1 & 2,14 & 0.947 & 0.2 & 2,14 & 0.803 & 0.3 & 2,14 & 0.759 \\
\hline
\end{tabular}
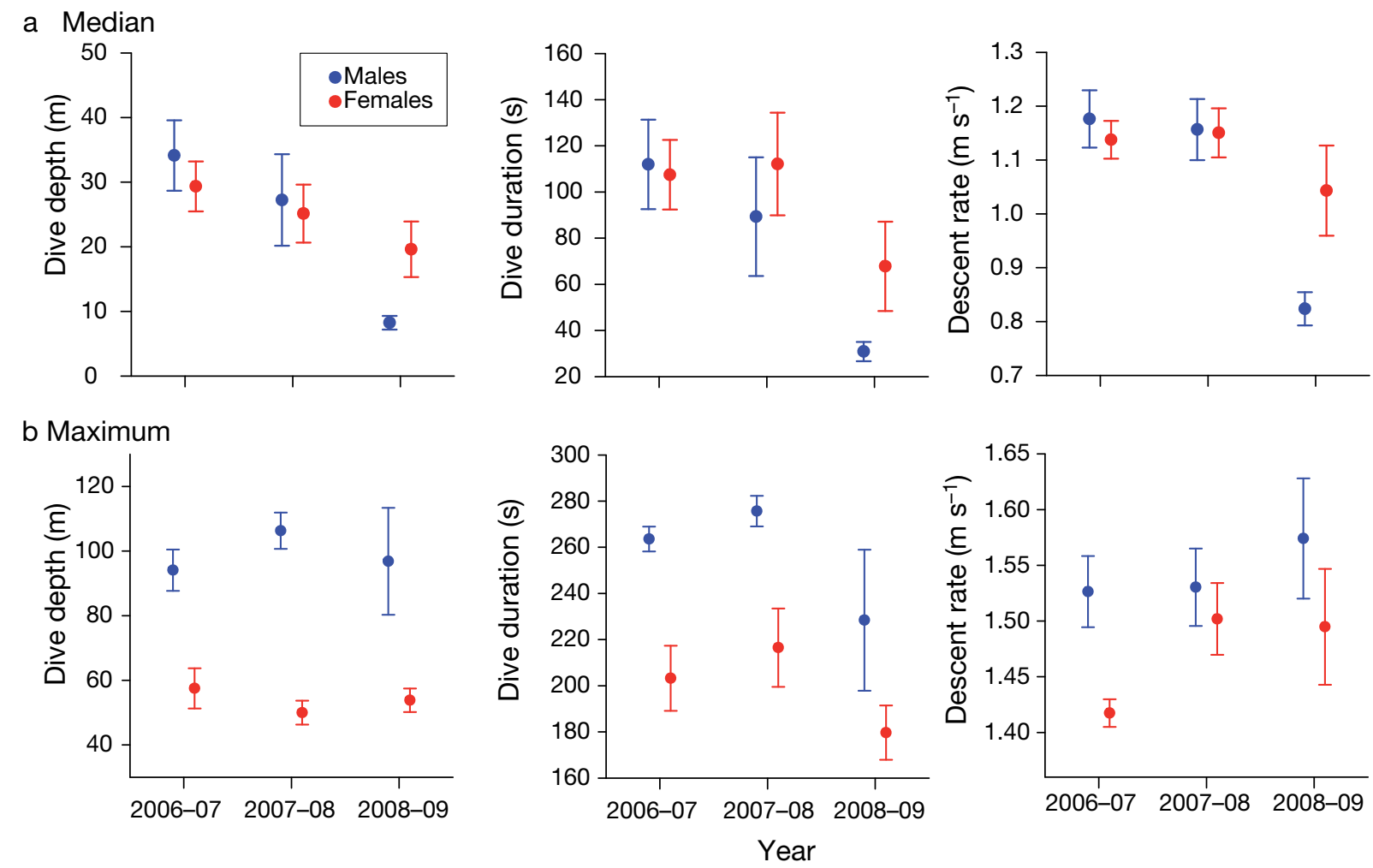

Fig. 2. Phalacrocorax atriceps albiventer. Three examples of (a) median and (b) maximum dive parameters separately by year and sex. One data-point per individual was used to calculate means and maxima (2007: 8 females, 7 males; 2008: 6 females, 6 males; 2009: 6 females, 5 males). For statistical details, see Table 2

0.001, males: $\chi^{2}=727, \mathrm{df}=4, \mathrm{p}<0.001$ ), and 2008-09 showed a particularly strong difference in this parameter from the other 2 breeding seasons. In both sexes, Dur1 dives were 2 times more common in 2008-09 than in other years; anaerobic Dur3 dives were nearly absent (Fig. 4).

\section{Stable isotope data}

Of the 10 median dive parameters listed in Table S1 in the Supplement, 8 were negatively related to $\delta^{13} \mathrm{C}$ of corresponding individuals (Fisher's omnibus test: $\mathrm{p}<$ 0.001), indicating lower (more negative) $\delta^{13} \mathrm{C}$ ratios 


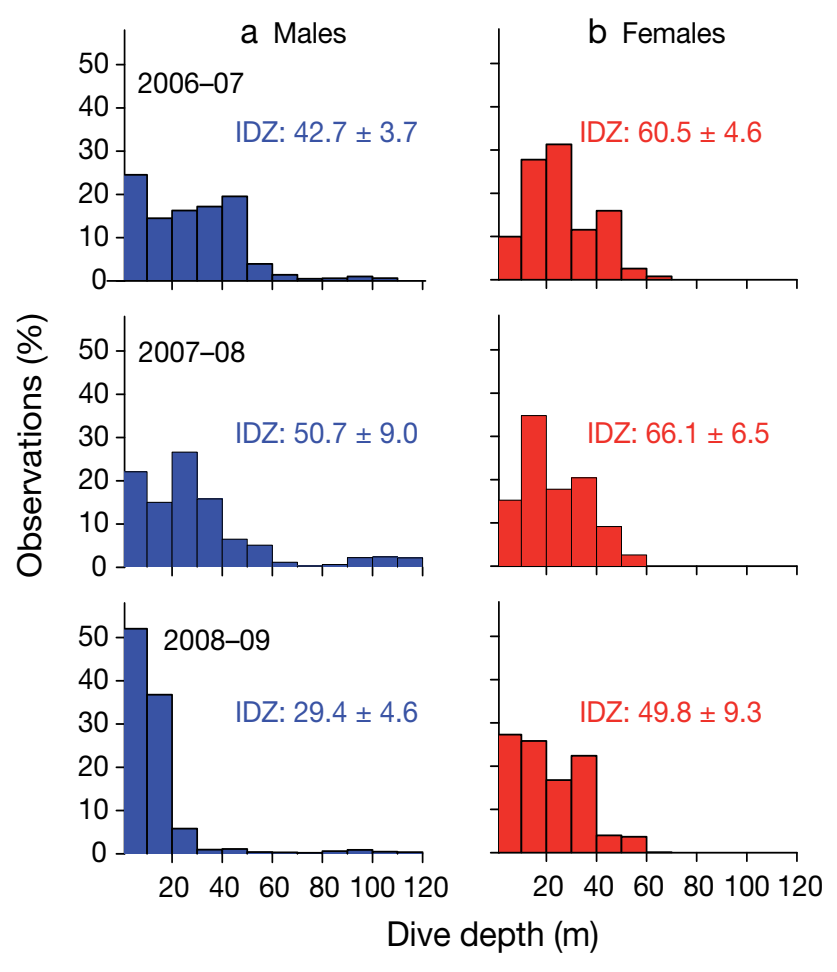

Fig. 3. Phalacrocorax atriceps albiventer. Distribution of dive depths of males and females. In total, 18767 dives were measured, evenly distributed among 11 to 15 individuals over 3 years. The proportion of intra-depth zone (IDZ) dives (in \%) indicates the prevalence of benthic diving behaviour, based on the assumption that benthic divers dive serially to a specific depth. The IDZ was defined as the depth $\pm 10 \%$ of the maximum depth reached by the preceding dive

with longer and deeper dives. This result was maintained when controlling for year and sex-related effects in a GLM. In contrast, none of the parameters were correlated with $\delta^{15} \mathrm{~N}$ (Fisher's omnibus test: $\mathrm{p}=$ 0.660).

$\delta^{13} \mathrm{C}$ varied among years (GLM, year effect: $F_{1,36}=$ 19.5, $\mathrm{p}<0.001, \chi^{2}=0.52$ ) and differed between sexes (sex effect: $F_{1,36}=12.4, \mathrm{p}=0.001, \chi^{2}=0.26$ ), with males showing lower $\delta^{13} \mathrm{C}$ (Fig. $5 \mathrm{~b}$ ). $\delta^{15} \mathrm{~N}$ also differed between sexes (GLM, sex effect: $F_{1,36}=7.9, p=0.008$, $\chi^{2}=0.18$ ), with males showing higher values (Fig. 5a). However, we detected no year-related differences in $\delta^{15} \mathrm{~N}$ (year effect: $F_{1,36}=1.8, \mathrm{p}=0.175, \chi^{2}=0.09$ ).

The stable isotope data of the 3 major prey types (fish, squid and lobster krill) were separated (Fig. 6), suggesting their suitability as sources in a mixing model. The distributions resulting from the SIAR stable isotope mixing model (Fig. 7) suggested that in 2008-09, males took $43 \%$ fish (95\% CI from 29 to $58 \%$ ), $26 \%$ squid (95\% CI from 9 to $43 \%$ ), and $31 \%$ lobster krill (95\% CI from 29 to $58 \%$ ). Females took slightly less fish (estimated mean $41 \%$; $95 \%$ CI from 27 to $53 \%$ ), much less squid (estimated mean $13 \%$; $95 \%$ CI from 0 to $27 \%$ ) and much more lobster krill (estimated mean 46\%; $95 \%$ CI from 31 to $61 \%$ ) than males.

\section{Adult condition, breeding success and sea surface temperatures}

Over the 3 year study, adults did not differ in body condition (body mass corrected for structural size) or body mass before or after the period of logger deployment (ANOVA separately for the sexes, all $\mathrm{p}>0.39$ ).

Breeding success was higher in 2007-08 (1.94 \pm 0.15 chicks per nest) than in the other 2 years (2006-07: $1.37 \pm 0.10$ and 2008-09: $1.39 \pm 0.13$ chicks per nest; ANOVA: $F_{116,2}=5.9, \mathrm{p}=0.004$; Tukey post hoc tests determined that 2007-08 was different from the other 2 years with $\mathrm{p}<0.05)$. The sea surface temperature during the chick-rearing season was lowest in 2007-08, intermediate in 2006-07 and highest in 2008-09 (Fig. 1c).

\section{DISCUSSION}

Owing not least to the advancement of data logger technology, our knowledge of the foraging ecology of marine apex predators has advanced greatly over the last decades. Studies of surface-feeding seabirds and epipelagic foraging marine mammals have documented the importance of oceanographic features such as continental shelf breaks (e.g. Suryan et al. 2006), and oceanographic conditions such as sea-surface temperature (Becker \& Beissinger 2003, Quillfeldt et al. 2007a).

There is, however, little information currently on the foraging habitat features selected by benthic- or demersal-feeding air-breathing predators (e.g. Arnould \& Kirkwood 2007 and references therein). We here studied sexually dimorphic imperial shags as a major benthic predator in a sub-Antarctic coastal habitat, to understand how intrinsic factors (sex-related differences) and extrinsic factors (year differences) influence the foraging behaviour of chick-provisioning males and females.

\section{Intrinsic factors: sex differences}

Differences in behaviour between the sexes can be caused by allometric relationships, e.g. faster flight or deeper dives by larger birds. Behavioural differences in monomorphic animals, however, clearly suggest that sexual differences can also be maintained by other intrinsic factors (e.g. Lewis et al. 2002). Of the sex differences we found in our study, the greater foraging 

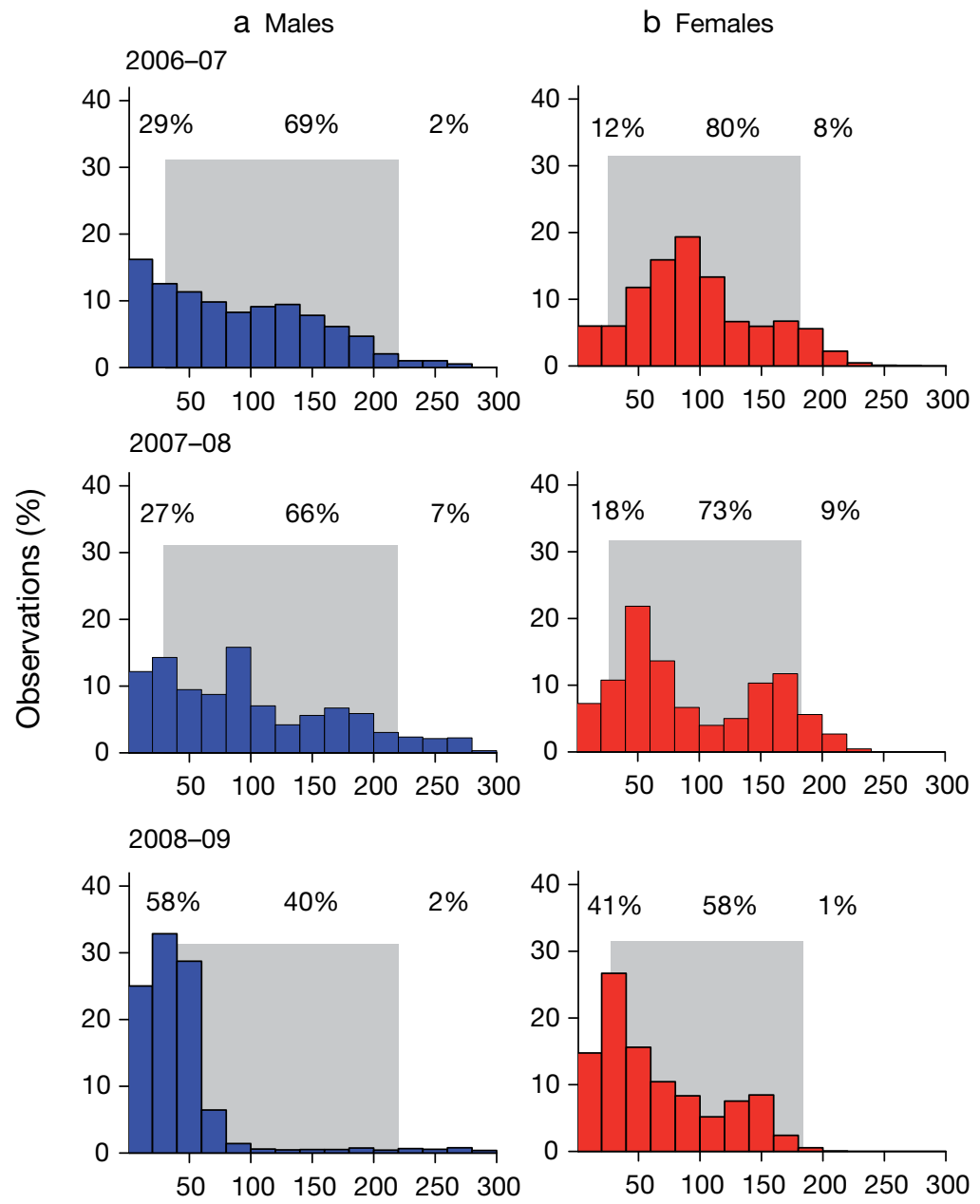

Dive duration (s)

Fig. 4. Phalacrocorax atriceps albiventer. Distribution of dive durations of males and females over the 3 year study period. Dive durations were classified as Dur1, Dur2 (marked with grey shading) and Dur3. Respective frequencies are given at the top of each panel

range, the greater dive ability and the higher trophic level might be explained by allometry, while the differences in foraging daytime, the greater actual dive performance (more time spent diving, deeper median dive depths) by females and the strong selection of coastal habitat by females are most likely explained by other mechanisms.

The larger foraging areas of male imperial shags observed by us in 2008-09 (Fig. 1) are in line with predictions from allometric relationships. A similar pattern was observed in Patagonian imperial shags by Quintana et al. (2011). Larger individuals can search larger areas per unit time and eat greater amounts and size ranges of prey. However, in 2 of the 3 years of our study, males did not make longer foraging trips, as females also covered nearly $50 \mathrm{~km}$ on their trips in coastal habitats (Table 3).
Consistent with allometry, we observed higher trophic levels in males in all 3 seasons, as indicated by higher $\mathrm{N}$ stable isotope values in the red blood cells (Fig. 5), suggesting that males took consistently larger prey. This has been observed previously in blue-eyed shags (reviewed by Cook et al. 2007), suggesting that males with their larger bills might be better able to catch larger-sized fish (e.g. Kato et al. 1996). The stable isotope mixing model for 2008-09 also suggested that females consumed greater amounts of the low-trophic-level lobster krill Munida gregaria. This crustacean can form large aggregations at the sea bottom, but also feeds in the water column. Due to its relatively tough exoskeleton, it is probably of lower nutritional value than fish, but provides a relatively stable food source.

We also found that male imperial shags - as expected due to their larger sizehad greater diving abilities, larger-bodied animals being able to load greater $\mathrm{O}_{2}$ stores and have lower mass-specific metabolic rates (e.g. Schreer \& Kovacs 1997). Physiological dive duration parameters (maximum DD:PDI ratio, bADL) differed accordingly between the sexes. We observed sex differences in maximum dive parameters such as the maximum dive depth (122 $\mathrm{m}$ in males vs. $97 \mathrm{~m}$ in females) and duration and maximum descent rate (Fig. 2b). Similar differences in maximum dive depth have been observed in other blue-eyed shags, such as Heard Island shags Phalacrocorax nivalis (Green \& Williams 1997: males $60 \mathrm{~m}$, females $33 \mathrm{~m}$ ), Macquarie Island king cormorants $P$. albiventer (Kato et al. 2000: males $109 \mathrm{~m}$, females $62 \mathrm{~m}$ ), and Crozet shags P. melanogenis (Cook et al. 2007: males $145 \mathrm{~m}$, females $55 \mathrm{~m}$ ), but not in Antarctic shags $P$. bransfieldensis (Casaux et al. 2001: males 110 m, females $113 \mathrm{~m}$ ). A recent study using acceleration data to estimate dive effort in imperial shag (Shepard et al. 2009, 2010) found that the degree to which time and energy costs diverge with depth will be a function of (1) the buoyancy of the study individual, and (2) the depth range used. But, how these parameters differ between female and male imperial shags needs to be explored in greater detail.

We observed a range of other sex-related differences, however, that are independent of differences in body size, or are even contrary to expected changes, viz. a greater actual dive performance by females, differ- 


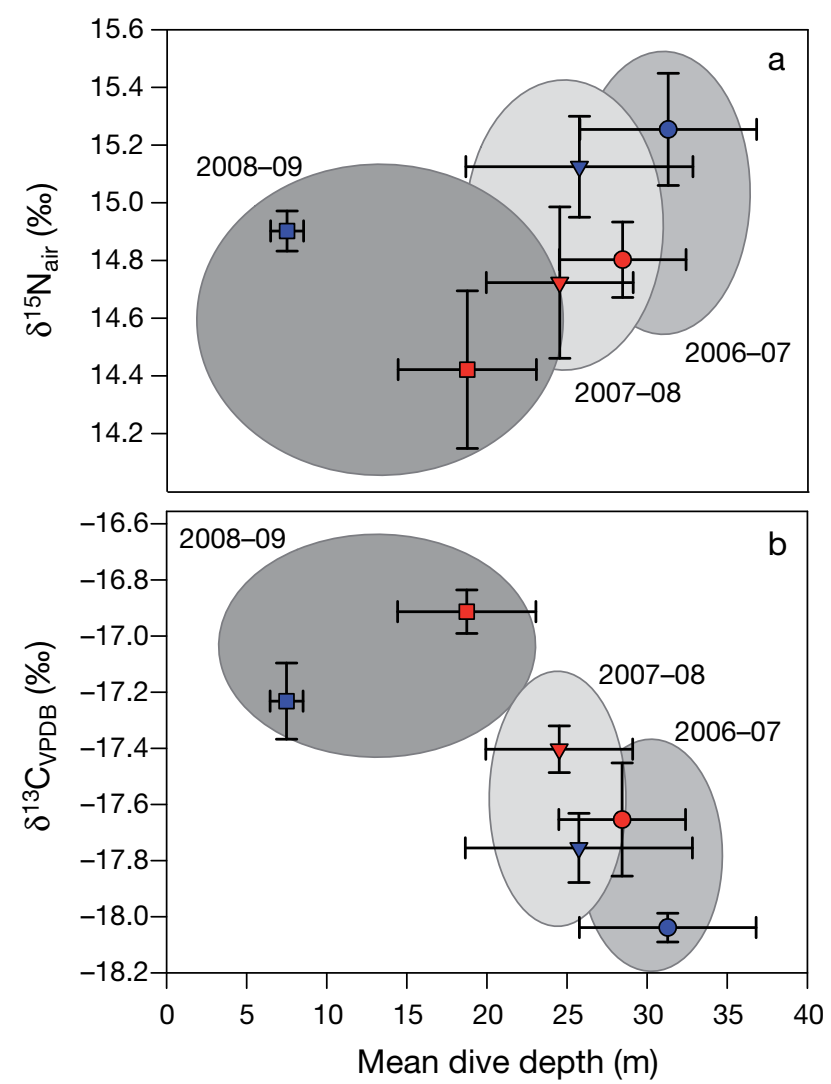

Fig. 5. Phalacrocorax atriceps albiventer. Stable isotope values in red blood cells of males (blue symbols) and females (red symbols) during the 3 year study period (2006-07: 0 , $\mathrm{n}=8$ males, 7 females; 2007-08: $\nabla, \mathrm{n}=6$ males, 6 females; 2008-09: $\square, \mathrm{n}=6$ males, 5 females). Shaded areas indicate what samples belong to each season

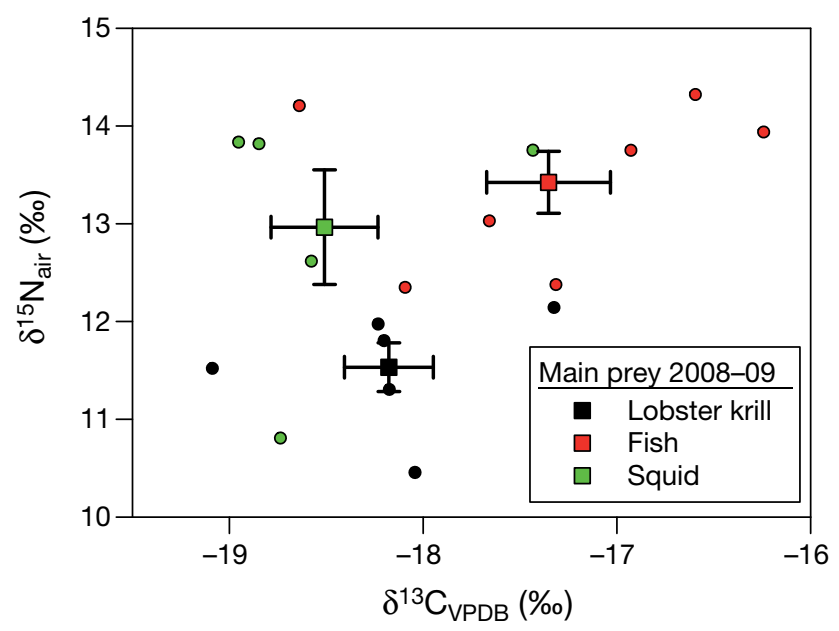

Fig. 6. Phalacrocorax atriceps albiventer. Stable isotope values of main types items, 2008-09: lobster krill Munida gregaria $(\mathrm{n}=6)$, Patagonian longfin squid Loligo gahi $(\mathrm{n}=5)$ and fish Agonopsis chiloensis $(\mathrm{n}=1)$, Cottoperca gobio $(\mathrm{n}=2)$, Patagonotothen squamiceps $(\mathrm{n}=1)$, Patagonotothen wiltoni $(\mathrm{n}=1)$, Sprattus fuegensis $(\mathrm{n}=1)$ and a member of the taxon Zoarcidae

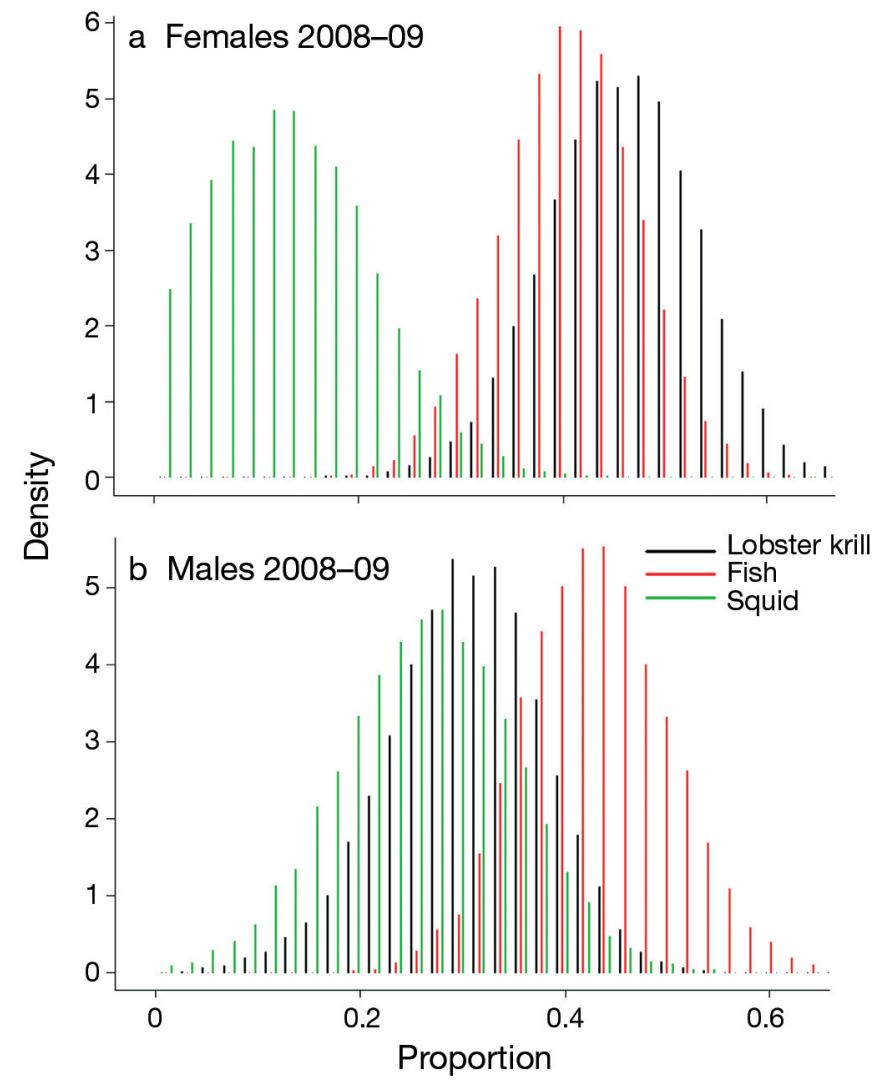

Fig. 7. Phalacrocorax atriceps albiventer. Density plots from the SIAR stable isotope mixing model, for contributions of main prey types to diet in 2008-09, based on red blood cell stable isotope values

ences in foraging daytime, and a strong selection of coastal habitat by females, as also reported for Patagonian imperial shags (Quintana et al. 2011). Offshore waters provide males with deep enough waters to make use of the full range of depths accessible to them, but also to reach pelagic food in productive waters. Being larger and faster, they might be better suited to catching such food than females, thus increasing the overall efficiency of parental investment across the breeding pair.

As males expanded their foraging range, they reduced dive depths, especially during 2008-09. Compared with females, males in the present study did not often make full use of their greater diving abilities. The observed mean dive depth, therefore, did not differ between the sexes in the present study (Table 3). This was mainly caused by a high percentage of shallow pelagic diving behaviour in males.

Similarly, despite diving abilities of up to $145 \mathrm{~m}$, Crozet shag males have been observed to carry out most of their dives in the shallowest depths, $52 \%$ of dives being to $<5 \mathrm{~m}$, while females dived mostly to a zone little used by males, viz. between 15 and $35 \mathrm{~m}$ 
(Cook et al. 2007). Deeper dives among females as opposed to males, including greater maximum dive depth, have also been observed in Antarctic shags (Casaux et al. 2001). This was explained by the distribution of smaller prey, which is favoured by females (e.g. Kato et al. 1996, Favero et al. 1998). Together, and consistent with our observations in 2008-09, these studies suggest that female blue-eyed shags often dive more deeply than males.

Overall, females demonstrated more energydemanding diving behaviour: females carried out more dives in all years (Table 2) and deeper and longer dives in a single year. In all years, they made more energy-demanding Dur2 dives. Males spent less time per day than females foraging and under water, and also spent less bottom time (Table 2) than females.

Wanless et al. (1992) suggested that most long dives in blue-eyed shags are anaerobic. We estimated that up to $9 \%$ of all dives in females were anaerobic; in males, this percentage was lower than in females in all years (Fig. S4 in the Supplement). This might suggest either that males can find sufficient food without diving as long, or that they avoid anaerobic dives.

The greater total time spent diving by females might be caused by several non-exclusive mechanisms. Females might respond to higher chick needs in the morning, with higher female investment thus resulting from temporal segregation in foraging between the sexes in this species. Males might also be able to use pelagic prey species more efficiently.

Studies comparing the provisioning rates between male and female blue-eyed shags would be useful in order to put differences in diving behaviour into the context of chick-provisioning effort. Such studies should take into account feeding frequencies and meal size. However, to our knowledge, only feeding frequencies have been reported for blue-eyed shag species (e.g. Kato et al. 2000).

We observed that the foraging daytime during chickrearing differed between the sexes. Females carried out the first foraging trip of the day, usually returning around noon to feed the chicks and stay at the nest, while the males foraged in the afternoon. Similar patterns have been observed in other blue-eyed shags (Anvers Island, Antarctica, Phalacrocorax bransfieldensis: Bernstein \& Maxon 1984; South Georgia, P. georgianus: Wanless et al. 1995; Heard Island, P. nivalis: Green \& Williams 1997; South Shetland Islands P. bransfieldensis: Favero et al. 1998; Macquarie Island, P. albiventer: Kato et al. 2000; Crozet, P. melanogenis: Cook et al. 2007). Thus, these patterns seem to have a strong genetic background (Cook et al. 2007). Temporal segregation between the sexes might be caused by diurnal patterns in the availability or behaviour of the main prey, notothenoid fish (Favero et al. 1998). It has also been suggested that males deliver larger prey items, and this might be more beneficial for the chicks in the afternoon, increasing the chances of survival to the following day (Bernstein \& Maxon 1984, Cook et al. 2007). However, males in the present study spent less time diving, and both sexes often carried out second or third foraging trips in a day, such that chicks did not necessarily receive their last meal or their largest meal from the male parent. The strongly synchronized diurnal patterns might have evolved, alternatively, if the females benefit more from replenishing their resources in the morning. This is likely, as females are smaller and thus have fewer body reserves. Also, the highly synchronized pattern might benefit females by avoiding conflicts over nest sites with the larger males. Mechanistically, these activity patterns should be reflected in different diurnal hormonal cycles between males and females (e.g. Quillfeldt et al. 2007b and references therein), a subject worth investigating.

\section{Extrinsic factors: Inter-annual differences in diving behaviour and foraging-space use}

Differences in foraging behaviour and prey choice among years of different environmental conditions and different availability of prey have been observed in many marine predators, and are basis for using apex predators as marine sentinels (Boyd et al. 2006). In the present study, we observed inter-annual differences in a range of parameters such as foraging distribution, parameters of foraging effort and dive parameters. The differences were particularly strong in males, while females changed their behaviour to a lesser degree.

The second year of our study, 2007-08, was marked by cold-water conditions with negative sea surface temperature anomalies (Fig. 1c). Sea surface temperature in the area has previously been suggested as an important driver of zooplankton abundance in this ecosystem (Quillfeldt et al. 2007a), which is more productive at lower water temperatures. The present data suggest that this also affects higher trophic levels, as shags had the highest breeding success in the coldwater year. Under these apparently favourable conditions in the year 2007-08, shags of both sexes foraged at the shortest distance from the coast (Fig. 1, Table 3). Such inter-annual differences in foraging-space use are in line with studies of other diving seabirds, and show that coastal species can use different areas depending on the available prey. For example, poorer conditions and inter-specific competition resulted in longer foraging trips and more offshore foraging in rock shags Phalacrocorax magellanicus (Quintana 2001, Frere et al. 2008). 
During the cold-water year 2007-08, on the other hand, imperial shags showed the highest rate of benthic diving (Table 2, Fig. 3). As the number of dives per day did not differ among years (Table 2), this resulted in a relatively long time spent under water per day. Thus, while this year would be classified 'low effort' based on trip lengths, it would be classified 'high effort' based on dive parameters.

The breeding season 2008-09 showed a strong contrast to this pattern, as males in particular carried out very long foraging trips, covering a larger offshore area than in the other 2 years; but exhibited a much higher proportion of shallow dives $(<10 \mathrm{~m}$ depth). Low IDZ values in that year indicated that the dives were predominantly pelagic (Fig. 3). Short underwater times in 2008-09 suggested good food availability in the pelagic food web. This was consistent with a high prevalence of pelagic prey in imperial shag regurgitates in 2008-09 (Michalik et al. 2010), including lobster krill, several species of squid and Patagonian sprat. (Diet studies from other years are, unfortunately, missing.) The more frequent use of pelagic prey was not, however, related to higher breeding success, and we therefore suggest that it was the best possible alternative under the circumstances ('best of a bad job' strategy), rather than being based on a preference.

The distribution of dive depths was either bimodal (2006-07 and 2007-08) or skewed to shallow dives (2008-09). Both distributions have been observed previously in blue-eyed shags. Kerguelen shags made mostly deep dives, with 1 peak at from 20 to $40 \mathrm{~m}$ and another at $\sim 90 \mathrm{~m}$ (Cook et al. 2008), similar to the distribution observed in our study in the first 2 years. A bimodal distribution was also observed in male imperial shags from Patagonia (Wilson \& Quintana 2004, Quintana et al. 2007). In contrast, Crozet shags showed - similar to our 2008-09 results - a skewed distribution of dive depths, with many shallow dives (Cook et al. 2007; Fig. 3). Thus, the inter-annual differences we observed strongly resembled differences previously observed between sites and species. The present results thus imply that differences in diving behaviour observed between study sites or species of blue-eyed shags based on a single year of measurements can result entirely from inter-year differences.

This is the first study on inter-annual variance in blue-eyed shag diving behaviour, but we can compare the present results with studies in other diving seabird species. Kato et al. (2001) recorded data on Japanese cormorants Phalacrocorax filamentosus over 4 summers. The birds fed mainly on epipelagic schooling fish. In a year of low pelagic fish availability, however, they took demersal fish, and tended to dive deeper and longer, reflecting the change in the depth distribution of their prey. As in the present study, Japanese cormorants specializing in coastal shallow waters made long dives, indicating that they were foraging in bottom layers, while those foraging in deeper shelf waters made short dives and they were thought to forage in surface layers (Ishikawa \& Watanuki 2002).

A recent study of gentoo penguins Pygoscelis papua (Miller et al. 2009) has yielded similar results. Over a 5 year period, Antarctic krill Euphausia superba was the primary diet item of these penguins in the South Shetland Islands, Antarctica, and fish the secondary. The distribution of dive depths was strongly skewed to shallow dives in 2 seasons with high krill availability, but was bimodal in years of low krill availability. Gentoo penguins share some features of their ecology with blue-eyed shags, specifically, a wide circumpolar distribution range in Antarctic and sub-Antarctic environments, but a restricted individual foraging range (e.g. Trivelpiece et al. 1987). Miller et al. (2009) suggested that the high flexibility in foraging behaviour of gentoo penguins provides an advantage in coping with different and rapidly changing environmental conditions, enabling them to maintain constant breeding success (Miller et al. 2009) and stable populations. In contrast, closely related species that show less flexible foraging behaviour, such as chinstrap penguins Pygoscelis antarctica (Miller \& Trivelpiece 2008), are less able to adapt and hence have declined as a consequence of climate change (e.g. Forcada et al. 2006, Hinke et al. 2007).

In the present study, the breeding success of imperial shags was higher in the second year (2007-08) than in the other 2 years, although comparable in most diving parameters to 2006-07 (e.g. Figs. 2 \& 3). Thus, like gentoo penguins (Miller et al. 2009), imperial shags are able to partially compensate for different prey availability through highly flexible foraging behaviour.

We also found inter-annual differences in stable isotope data (Fig. 5). However, interpreting these differences in terms of diet composition and pelagic vs. benthic diving can be difficult, as year differences might be caused by differences in baseline isotopic levels. Thus, unless baseline data are available from each year and food web in a comparison, only relative differences can be compared. In the present study, the relative differences between males and females were similar across the years, with males maintaining consistently higher $\delta^{15} \mathrm{~N}$ and lower $\delta^{13} \mathrm{C}$, indicating a higher trophic level. The lower $\delta^{13} \mathrm{C}$ values could be caused by more pelagic foraging or more squid in the diet.

We further found a negative correlation between $\delta^{13} \mathrm{C}$ ratios in individuals and their dive depths, even when controlling for year and sex effects. This is 
counter-intuitive, as deep dives should reach the benthic food web, and thus a positive correlation would be expected. The present results are most likely explained by differences in prey choice, especially more squid with low $\delta^{13} \mathrm{C}$ values in males. The results suggest that squid, despite the lower (i.e. more pelagic) $\delta^{13} \mathrm{C}$ values might be captured at greater depths than fish or lobster krill. This is consistent with the diel migrations of squid that come to feed at the sea surface at night, but spend the day in deeper waters. These hypotheses could be tested by more targeted dietary sampling of individual birds equipped with data loggers when returning to their nest sites.

\section{CONCLUSIONS}

The main findings of this study are:

(1) In line with the pattern expected by their larger body mass, male imperial shags are able to dive deeper and for a longer period than females. Nevertheless, the data suggest that females perform more energetically expensive dives. However, the observed bahaviour varied strongly among years.

(2) Blue-eyed shags are known as a major coastal benthic predator. However, in the present study on imperial shags, pelagic diving was also common, and prominent in 1 year. Contrary to expectation, the larger male imperial shags made more extensive use of the pelagic food chain than the females. It is not known whether imperial shags prefer pelagic or benthic prey, or opportunistically take the prey that is more easily available.

(3) The most striking feature of the at-sea movements by female imperial shags observed in the present study is their exclusive use of coastal waters between the islands. Here, females employed mainly benthic diving, showing relatively constant foraging behaviour among years. Males were much more flexible during any year, with more pelagic foraging behaviour and more time spent in offshore areas over deep water. The overlap in coastal foraging areas speaks against interference competition, which predicts that the larger males would force females to forage elsewhere. In contrast, we found that males moved, while females stayed.

The results are therefore in line with theoretical considerations and empirical data suggesting that smaller animals should be superior in exploitative competition (Persson 1985). Although we have no direct evidence of exploitative competition between male and female imperial shags, the present data suggest that the larger males travel farther to offshore areas to use alternative prey patches when available.
Acknowledgements. We are grateful to the following organizations and persons: New Island Conservation Trust, and I., M. and G. Strange, as well as D. Birch, who facilitated work at New Island. Financial support came from DFG, Germany (Qu 148/1ff); T. Mattern supplied the Matlab script. We gratefully acknowledge the excellent technical help of G. Peters, of Earth \& Ocean Technologies. The stable isotope analysis was carried out by R. McGill at the Scottish Universities Environmental Research Centre, Glasgow, and was funded by NERC, UK. We thank B. Furness and T. Eggers for their support. Fieldwork at New Island was approved by the Falkland Islands Environmental Planning Office. The manuscript benefited from the comments of 4 anonymous reviewers and the subject editor.

\section{LITERATURE CITED}

Arnould JPY, Kirkwood R (2007) Habitat selection by female Australian fur seals (Arctocephalus pusillus doriferus). Aquatic Conserv: Mar Freshw Ecosyst 17:S53-S67

Beck CA, Bowen WD, McMillan JI, Iverson SJ (2003) Sex differences in the diving behaviour of a size-dimorphic capital breeder: the grey seal. Anim Behav 66:777-789

$>$ Becker BH, Beissinger SR (2003) Scale-dependent habitat selection by a nearshore seabird, the marbled murrelet, in a highly dynamic upwelling system. Mar Ecol Prog Ser 256:243-255

Bernstein NP, Maxson SJ (1984) Sexually distinct daily activity patterns of blue-eyed shags in Antarctica. Condor 86: $151-156$

Beyer HL (2004) Hawth's analysis tools for ArcGIS. http:// www.spatialecology.com/htools

Boyd IL, Wanless S, Camphuysen CJ (eds) (2006) Top predators in marine ecosystems: their role in monitoring and management. Cambridge University Press, Cambridge

Casaux R, Barrera-Oro ER (2006) Shags in Antarctica: their feeding behaviour and ecological role in the marine food web. Antarct Sci 18:3-14

Casaux R, Favero M, Silva P, Baroni A (2001) Sex differences in diving depths and diet of Antarctic shags at the South Shetland Islands. J Field Ornithol 72:22-29

Caut S, Angulo E, Courchamp F (2009) Variation in discrimination factors $\left(\delta^{15} \mathrm{~N}\right.$ and $\left.\delta^{13} \mathrm{C}\right)$ : the effect of diet isotopic values and applications for diet reconstruction. J Appl Ecol 46:443-453

Clutton-Brock TH, Guinness FE, Albon SD (1982) Red deer: behaviour and ecology of two sexes. The University of Chicago Press, Chicago

Cook TR, Cherel Y, Tremblay Y (2005) Foraging tactics of chick-rearing Crozet shags: individuals display repetitive activity and diving patterns over time. Polar Biol 29: 562-569

Cook TR, Cherel Y, Bost CA, Tremblay Y (2007) Chickrearing Crozet shags (Phalacrocorax melanogenis) display sex-specific foraging behaviour. Antarct Sci 19:55-63

Cook TR, Lescroel A, Tremblay Y, Bost CA (2008) To breathe or not to breathe? Optimal breathing, aerobic dive limit and oxygen stores in deep-diving blue-eyed shags. Anim Behav 76:565-576

Croll DA, Gaston AJ, Burger AE, Konnoff D (1992) Foraging behavior and physiological adaptation for diving in thickbilled murres. Ecology 73:344-356

de Solla SR, Bonduriansky R, Brooks RJ (1999) Eliminating autocorrelation reduces biological relevance of home range estimates. J Anim Ecol 68:221-234

> Engqvist L (2005) The mistreatment of covariate interaction terms in linear model analyses of behavioural and evolutionary ecology studies. Anim Behav 70:967-971

Enstipp MR, Gremillet D, Jones DR (2006) The effects of depth, 
temperature and food ingestion on the foraging energetics of a diving endotherm, the double-crested cormorant (Phalacrocorax auritus). J Experim Biol 209: 845-859

Favero M, Casaux R, Silva P, Barrera-Oro E, Coria N (1998) The diet of the Antarctic shag during summer at Nelson Island, Antarctica. Condor 100:112-118

Ferrari S, Alegre B, Gandini P (2004) The diet of imperial cormorant (Phalacrocorax atriceps) in southern Santa Cruz (Patagonia, Argentina). Ornitol Neotrop 15:103-110

Forcada J, Trathan PN, Reid K, Murphy EJ, Croxall JP (2006) Contrasting population changes in sympatric penguin species in association with climate warming. Glob Change Biol 12:411-423

Frere E, Quintana F, Gandini P, Wilson RP (2008) Foraging behaviour and habitat partitioning of two sympatric cormorants in Patagonia, Argentina. Ibis 150:558-564

Fretwell SD, Lucas HL Jr (1969) On territorial behaviour and other factors influencing habitat distribution in birds. Acta Biotheor 19:16-36

González-Solís J, Croxall JP, Wood AG (2000) Sexual dimorphism and sexual segregation in foraging strategies of northern giant petrels, Macronectes halli, during incubation. Oikos 90:390-398

- Green K, Williams R (1997) Biology of the Heard Island Shag Phalacrocorax nivalis: 3. Foraging, diet and diving behaviour. Emu 97:76-83

Grémillet D, Wanless S, Carss DN, Linton D, Harris MP, Speakman JR, Le Maho Y (2001) Foraging energetics of arctic cormorants and the evolution of diving birds. Ecol Lett 4:180-184

Haccou P, Meelis E (1994) Statistical analysis of behavioural data: an approach based on time-structured models. Oxford University Press, Oxford

> Heithaus MR, Wirsing AJ, Burkholder D, Thomson J, Dill LM (2009) Towards a predictive framework for predator risk effects: the interaction of landscape features and prey escape tactics. J Anim Ecol 78:556-562

Hinke JT, Salwicka K, Trivelpiece SG, Watters GM, Trivelpiece WZ (2007) Divergent responses of Pygoscelis penguins reveal a common environmental driver. Oecologia 153:845-855

Hobson KA, Clark RG (1993) Turnover of ${ }^{13} \mathrm{C}$ in cellular and plasma reactions of blood: implications for nondestructive sampling in avian dietary studies. Auk 110:638-641

Inger R, Bearhop S (2008) Applications of stable isotope analyses to avian ecology. Ibis 150:447-461

Ishikawa K, Watanuki Y (2002) Sex and individual differences in foraging behavior of Japanese cormorants in years of different prey availability. J Ethol 20:49-54

Jenkins JM (1979) Foraging behavior of male and female Nuttall woodpeckers. Auk 96:418-420

Kato A, Nishiumi I, Naito Y (1996) Sexual differences in the diet of king cormorants at Macquarie Island. Polar Biol $16: 75-77$

Kato A, Watanuki Y, Shaughnessy P, Maho YL, Naito Y (1999) Intersexual differences in the diving behaviour of foraging subantarctic cormorant (Phalacrocorax albiventer) and Japanese cormorant (P. filamentosus). C R Acad Sci Paris. Sci Vie 322:557-562

Kato A, Watanuki Y, Nishiumi I, Kuroki M, Naito Y (2000) Variation in foraging and parental behavior of king cormorants. Auk 117:718-730

Kato A, Watanuki Y, Naito Y (2001) Foraging and breeding performance of Japanese cormorants in relation to prey type. Ecol Res 16:745-758

Kooyman GL, Kooyman TG (1995) Diving behaviour of Emperor penguins nurturing chicks at Coulman Island, Antarctica. Condor 97:536-549
Kooyman GL, Ponganis PJ (1990) Behavior and physiology of diving in emperor and king penguins. In: Davis LS, Darby J (eds) Penguin Biology. Academic Press, New York, p 229-242

> Kooyman GL, Wahrenbrock EA, Castellini MA, Davis RW, Sinnett EE (1980) Aerobic and anaerobic metabolism during voluntary diving in Weddell seals: evidence of preferred pathways from blood chemistry and behavior. J Comp Physiol B 138:335-346

Kooyman GL, Castellini MA, Davis RW, Maure RA (1983) Aerobic diving limits of immature Weddell seals. J Comp Physiol 151:171-174

Le Boeuf BJ, Crocker DE, Costa DP, Blackwell SB, Webb PM, Houser DS (2000) Foraging ecology of northern elephant seals. Ecol Monogr 70:353-382

Lewis S, Benvenuti S, Dall'Antonia L, Griffith R and others (2002) Sex-specific foraging behaviour in a monomorphic seabird. Proc Biol Sci 269:1687-1693

MacArthur RH, Pianka ER (1966) On optimal use of a patchy environment. Am Nat 100:603-609

Malacalaza VE, Hall MA (1988) Sexing adult king cormorants (Phalacrocorax albiventer) by discriminant analysis. Colon Waterbirds 11:32-37

Malacalaza VE, Poretti TI, Bertellotti NM (1994) La dieta de Phalacrocorax albiventer en Punta León (Chubut, Argentina) durante la temporada reproductiva. Ornitol Neotrop 5:91-97

Masello JF, Mundry R, Poisbleau M, Demongin L, Voigt C, Wikelski M, Quillfeldt P (2010) Diving seabirds share foraging space and time within and among species. Ecosphere 1:19

Mattern T, Ellenberg U, Houston DM, Davis LS (2007) Consistent foraging routes and benthic foraging behaviour in yellow-eyed penguins. Mar Ecol Prog Ser 343:295-306

Michalik A, van Noordwijk H, Brickle P, Eggers T, Quillfeldt P (2010) The diet of the imperial shag Phalacrocorax atriceps at a colony on New Island, Falkland/Malvinas Islands combining different sampling techniques. Polar Biol 33: $1537-1546$

- Miller AK, Trivelpiece WZ (2008) Chinstrap penguins alter foraging and diving behavior in response to the size of their principle prey, Antarctic krill. Mar Biol 154:201-208

Miller AK, Karnovsky NJ, Trivelpiece WZ (2009) Flexible foraging strategies of gentoo penguins Pygoscelis papua over five years in the South Shetland Islands, Antarctica. Mar Biol 156:2527-2537

Minagawa M, Wada E (1984) Stepwise enrichment of ${ }^{15} \mathrm{~N}$ along food chains: further evidence and the relation between $\delta^{15} \mathrm{~N}$ and animal age. Geochim Cosmochim Acta 48:1135-1140

Moore JW, Semmens BX (2008) Incorporating uncertainty and prior information into stable isotope mixing models. Ecol Lett 11:470-480

Owens NJP (1987) Natural variations in ${ }^{15} \mathrm{~N}$ in the marine environment. Adv Mar Biol 24:389-451

Parnell A, Inger R, Bearhop S, Jackson AL (2008) Stable isotope analysis in R (SIAR). http://cran.r-project.org/web/ packages/siar/index.html

> Persson L (1985) Asymmetrical competition: Are larger animals competitively superior? Am Nat 126:261-266

Ponganis PJ, Kooyman GL, Starke LN, Kooyman CA, Kooyman TG (1997) Post-dive blood lactate concentrations in emperor penguins, Aptenodytes forsteri. J Exp Biol 200: 1623-1626

Punta G, Yorio P, Herrera G (2003) Temporal patterns in the diet and food partitioning in imperial cormorants (Phalacrocorax atriceps) and rock shags (P. magellanicus) breeding at Bahía Bustamante, Argentina. Wilson Bull 115:307-315 
Quillfeldt P, McGill RAR, Furness RW (2005) Diet and foraging areas of Southern Ocean seabirds and their prey inferred from stable isotopes: review and case study of Wilson's storm-petrel. Mar Ecol Prog Ser 295:295-304

Quillfeldt P, Strange IJ, Masello JF (2007a) Sea surface temperatures and behavioural buffering capacity in thinbilled prions Pachyptila belcheri: breeding success, provisioning and chick begging. J Avian Biol 38:298-308

Quillfeldt P, Poisbleau M, Chastel O, Masello JF (2007b) Corticosterone in thin-billed prion Pachyptila belcheri chicks: diel rhythm, timing of fledging and nutritional stress. Naturwissenschaften 94:919-925

Quillfeldt P, McGill R, Strange IJ, Masello JF, Weiss F, Brickle P, Furness RW (2008) Stable isotope analysis reveals sexual and environmental variability and individual consistency in foraging of thin-billed prions. Mar Ecol Prog Ser 373:137-148

Quinn GP, Keough MJ (2002) Experimental design and data analysis for biologists. Cambridge University Press, Cambridge

Quintana F (2008) Foraging behaviour and feeding locations of rock shags (Phalacrocorax magellanicus) from a colony in Patagonia, Argentina. Ibis 143:547-553

> Quintana F, Wilson RP, Yorio P (2007) Dive depth and plumage air in wettable birds: the extraordinary case of the imperial cormorant. Mar Ecol Prog Ser 334:299-310

Quintana F, Wilson RP, Dell'Archipetre P, Shepard E, Gómez Laigh A (2011) Women from Venus, men from Mars: intersex foraging differences in the imperial cormorant Phalacrocorax atriceps, a colonial seabird. Oikos 120:350-358

R Development Core Team 2009. R: a language and environment for statistical computing. R Foundation for Statistical Computing, Vienna, Austria.

Ropert-Coudert Y, Wilson RP, Daunt F, Kato A (2004) A finescale time budget of Cape gannets provides insight into the foraging strategies of coastal seabirds. Anim Behav 67:985-992

Schoener TW (1971) Theory of feeding strategies. Annu Rev Ecol Syst 2:369-404

Schreer JF, Kovacs KM (1997) Allometry of diving capacity in air-breathing vertebrates. Can J Zool 75:339-358

Schreiber EA, Burger J (2001) Biology of marine birds. CRC Press, Boca Raton

Shaffer SA, Weimerskirch H, Costa DP (2001) Functional significance of sexual dimorphism in wandering albatrosses, Diomedea exulans. Funct Ecol 15:203-210

Shepard ELC, Wilson PR, Quintana F, Gómez Laich A, Forman DW (2009) Pushed for time or saving on fuel: finescale energy budgets shed light on currencies in a diving bird. Proc Biol Sci 276:3149-3155

Shepard ELC, Wilson PR, Gómez Laich A, Quintana F (2010) Buoyed up and slowed down: speed limits for diving birds in shallow water. Aquat Biol 8:259-267

Siegel-Causey D (1988) Phylogeny of the Phalacrocoracidae. Condor 90:885-905

Suryan RM, Sato F, Balogh GR, Hyrenbach KD, Sievert PR, Ozaki K (2006) Foraging destinations and marine habitat use of short-tailed albatrosses: a multi-scale approach using first-passage time analysis. Deep-Sea Res II 53: 370-386

Svagelj W, Quintana F (2007) Sexual size dimorphism and sex determination by morphometric measurements in breeding imperial shags (Phalacrocorax atriceps). Waterbirds 30:97-102

Takahashi A, Sato K, Naito Y, Dunn MJ, Trathan PN, Croxall JP (2004) Penguin-mounted cameras glimpse underwater

Editorial responsibility: Rory Wilson,

Swansea, UK group behaviour. Proc Biol Sci 271(Suppl):S281-S282

Thaxter CB, Daunt F, Hamer KC, Watanuki Y and others (2009) Sex-specific food provisioning in a monomorphic seabird, the common guillemot Uria aalge: Nest defence, foraging efficiency or parental effort? J Avian Biol 40: $75-84$

Thompson KR (1989) An assessment of the potential for competition between seabirds and fisheries in the Falkland Islands. Falkland Islands Foundation, Brighton, UK

Thompson KR (1994) Predation on Gonatus antarcticus by Falkland Islands seabirds. Antarct Sci 6:269-274

Tremblay Y, Cherel Y (2000) Benthic and pelagic dives: a new foraging behaviour in rockhopper penguins. Mar Ecol Prog Ser 204:257-267

> Tremblay Y, Cook TR, Cherel Y (2005) Time budget and diving behaviour of chick-rearing Crozet shags. Can J Zool 83:971-982

Trivelpiece WZ, Trivelpiece SG, Volkman NJ (1987) Ecological segregation of Adelie, gentoo and chinstrap penguins at King George Island, Antarctica. Ecology 68:351-361

Van Tets GF (1976) Australasia and the origin of shags and cormorants, Phalacrocoracidae. In: Frith HV, Calaby JH (eds) Proc 16th Ann Ornith Congr, Canberra, p 121-124

- Walton P, Ruxton GD, Monaghan P (1998) Avian diving, respiratory physiology and the marginal value theorem. Anim Behav 56:165-174

Wanless S, Harris MP, Morris JA (1992) Diving behaviour and diet of the blue-eyed shag at South Georgia. Polar Biol 12:713-719

- Wanless S, Harris MP, Morris JA (1995) Factors affecting daily activity budgets of South Georgian shags during chick rearing at Bird Island, South Georgia. Condor 97:550-558

- Watanuki Y, Kato A, Naito Y (1996) Diving performance of male and female Japanese cormorants. Can J Zool 74: 1098-1109

Weimerskirch H, Cherel Y, Cuenot-Chaillet F, Ridoux V (1997) Alternative foraging strategies and resource allocation by male and female wandering albatrosses. Ecology 78:2051-2063

Willmer P, Stone G, Johnston IA (2005) Environmental physiology of animals, 2nd edn. Blackwell Publishing, Malden, Massachusetts

Wilson RP (1995) Foraging ecology. In: Williams TD (ed) The penguins. Oxford University Press, Oxford, p 81-106

Wilson RP, Quintana F (2004) Surface pauses in relation to dive duration in imperial cormorants: How much time for a breather? J Exp Biol 207:1789-1796

Wilson RP, Wilson MP (1988) Dead reckoning: a new technique for determining penguin movements at sea. Meeresforschung 32:155-158

Wilson RP, Wilson MPT, Link R, Mempel H, Adams NJ (1991) Determination of movements of African penguins Spheniscus demersus using a compass system: Dead reckoning may be an alternative to telemetry. J.Exp.Biol 157:557-564

Woo K, Kober K, Gaston AJ (1999) Difference in timing of incubation shifts between male and female thick-billed murres are associated with variation in maximum diving depth. Pacific Seabirds 26:55

> Wood AG, Naef-Daenzer B, Prince PA, Croxall JP (2000) Quantifying habitat use in satellite-tracked pelagic seabirds: application of kernel estimation to albatross locations. J Avian Biol 31:278-286

> Yorio P, Copello S, Kuba L, Gosztonyi A, Quintana F (2010) Diet of imperial cormorants Phalacrocorax atriceps breeding at central Patagonia, Argentina. Waterbirds 33: $70-78$

Submitted: July 12, 2010; Accepted: January 22, 2011

Proofs received from author(s): April 8, 2011 